\title{
Ion Current Density Study of the NASA-300M and NASA-457Mv2 Hall Thrusters
}

\author{
Wensheng Huang ${ }^{*}$, Rohit Shastry ${ }^{\dagger}$, Daniel A. Herman ${ }^{\ddagger}$, George C. Soulas ${ }^{\S}$, and Hani Kamhawi** \\ National Aeronautics and Space Administration Glenn Research Center, Cleveland, Ohio, 44135
}

NASA Glenn Research Center is developing a Hall thruster in the $15-50 \mathrm{~kW}$ range to support future NASA missions. As a part of the process, the performance and plume characteristics of the NASA-300M, a 20-kW Hall thruster, and the NASA-457Mv2, a 50-kW Hall thruster, were evaluated. The collected data will be used to improve the fidelity of the JPL modeling tool, Hall2De, which will then be used to aid the design of the $15-50 \mathrm{~kW}$ Hall thruster. This paper gives a detailed overview of the Faraday probe portion of the plume characterization study. The Faraday probe in this study is a near-field probe swept radially at many axial locations downstream of the thruster exit plane. Threshold-based integration limits with threshold values of $1 / \mathrm{e}, 1 / \mathrm{e}^{2}$, and $1 / \mathrm{e}^{3}$ times the local peak current density are tried for the purpose of ion current integration and divergence angle calculation. The NASA-300M is operated at 7 conditions and the NASA-457Mv2 at 14 conditions. These conditions span discharge voltages of 200 to $500 \mathrm{~V}$ and discharge power of 10 to $50 \mathrm{~kW}$. The ion current density profiles of the near-field plume originating from the discharge channel are discovered to strongly resemble Gaussian distributions. A novel analysis approach involving a form of ray tracing is used to determine an effective point of origin for the nearfield plume. In the process of performing this analysis, definitive evidence is discovered that showed the near-field plume is bending towards the thruster centerline.

\begin{tabular}{llll}
\multicolumn{4}{c}{ Abbreviations and Nomenclature } \\
GRC & $=$ Glenn Research Center & $\theta$ & $=$ polar angle \\
HEFT & $=$ Human Exploration Framework Team & $\mathrm{j}_{\mathrm{z}}$ & $=$ axial ion current density \\
$\mathrm{ISP}$ & $=$ In Space Propulsion Program & $\mathrm{Z}$ & $=$ axial coordinate \\
$300 \mathrm{M}$ & $=$ NASA-300M & $\mathrm{r}$ & $=$ radial coordinate \\
$457 \mathrm{Mv2}$ & $=$ NASA-457Mv2 & $\mathrm{Z}$ & $=$ normalized axial coordinate \\
$\mathrm{T}$ & & (normalized by mean thruster diameter) \\
$\dot{\mathrm{m}}_{\mathrm{a}}$ & $=$ thrust & $\mathrm{R}$ & $=$ normalized radial coordinate \\
$\mathrm{I}_{\mathrm{d}}$ & $=$ discharge current & & (normalized by mean thruster diameter) \\
$\mathrm{V}_{\mathrm{d}}$ & $=$ discharge voltage & \\
$\delta$ & $=$ charged-weighted divergence angle & &
\end{tabular}

\section{Introduction}

TN 2010, NASA established the Human Exploration Framework Team (HEFT) to analyze exploration and Itechnology concepts and provide inputs to the agency's senior leadership on the key components of a safe, sustainable, affordable, and credible future human space exploration endeavor for the nation. ${ }^{1}$ The team concluded, in part, that the use of a high power (i.e. on the order of $300 \mathrm{~kW}$ ) solar electric propulsion system could significantly reduce the number of heavy lift launch vehicles required for a human mission to a near earth asteroid. ${ }^{1,2}$ Hall thrusters were found to be ideal for such applications because of their high power processing capabilities and their

\footnotetext{
* Research Engineer, Propulsion and Propellants, wensheng.huang@nasa.gov, AIAA Member.

${ }^{\dagger}$ Research Engineer, Propulsion and Propellants, rohit.shastry@ nasa.gov, AIAA Member.

* Research Engineer, Propulsion and Propellants, daniel.a.herman@ nasa.gov, AIAA Senior Member.

${ }^{\S}$ Research Engineer, Propulsion and Propellants, george.c.soulas@nasa.gov, AIAA Member.

** Research Engineer, Propulsion and Propellants, hani.kamhawi-1@ nasa.gov, AIAA Associate Fellow.
} 
efficient operation at moderate specific impulses, which leads to reduced trip times that are necessary for such missions. ${ }^{2-4}$ Recent electric propulsion system model estimates that considered factors such as cost, mass, faulttolerance, cost uncertainty, complexity, ground test vacuum facility limitations, previously demonstrated power capabilities, and possible technology limitations have shown that Hall thrusters operating at power levels of 20-50 $\mathrm{kW}$ are strong candidates for human exploration missions operating at total powers up to $500 \mathrm{~kW}$. $^{2,5}$

Two NASA Hall thrusters are considered strong candidates for the aforementioned mission, the NASA-300M and the NASA-457Mv2. The NASA-300M is a $20-\mathrm{kW}$-class thruster, while the NASA-457Mv2 is a $50-\mathrm{kW}$-class thruster. The NASA-457M, predecessor to the NASA-457Mv2, was first developed and tested in the 2000-2003 time frame as a part of the Space Solar Power Concept and Technology Maturation Program. ${ }^{6}$ The NASA-457Mv2, which was an improved version of the NASA-457M, was not thoroughly tested prior to program termination. The NASA-300M was developed from 2004 to 2005 for project Prometheus but was not tested until recently due to project cancellation. ${ }^{7}$ With the recent renewal in interest toward high-power Hall thrusters, the performance of the NASA-300M was characterized in $2010^{7}$ and the performance of the NASA-457Mv2 was characterized in $2011 .^{8}$

To respond to the call of the HEFT, the NASA Glenn Research Center (GRC) is partnering with the Jet Propulsion Laboratory (JPL) to study the above two Hall thrusters. Information obtained from said studies will then be used to validate and improve the fidelity of the JPL modeling tool, Hall2De. The combination of empirical and simulation data will be used to develop a highly-throttleable, long-life Hall thruster in the 15-50 kW range.

In particular, the development team wishes to integrate the recent discovery of the use of magnetic shielding in designing a long-life Hall thruster. Since magnetic shielding was originally discovered on a $4.5-\mathrm{kW}$ Hall thruster, ${ }^{9}$ the first step is to confirm that the principles of magnetic shielding can be scaled up to a few tens of kilowatts. Further details on the principles of magnetic shielding can be found in an article by Mikellides, et al. ${ }^{9}$

To refine Hall2De as a design tool for magnetically shielded Hall thrusters, near-field plasma-diagnostics tests were performed on both the NASA-300M and the NASA-457Mv2 Hall thrusters. The diagnostics used during these tests include Faraday probe, Langmuir probe, and emissive probe. These diagnostics were mounted on a two-axis positioning system that can move quickly in the radial direction. Two ExB probes and a retarding potential analyzer were also mounted in the far-field. This paper will focus on the near-field Faraday-probe portion of the studies performed on the NASA-300M and NASA-457Mv2. There have been at least four previous instances of near-field Faraday-probe testing in a Hall thruster environment. ${ }^{10-13}$ The test methodology and data analysis carried out for this paper draws heavily from the knowledge gained during those tests.

\section{Experimental Setup}

For the sake of brevity and to simplify plot labeling, NASA-300M will sometimes be referred to as the $300 \mathrm{M}$ and NASA-457Mv2 as the $457 \mathrm{Mv} 2$ in this paper. Operating conditions are labeled as www V, yy.y A, where www is the discharge voltage in volts and yy.y is the discharge current in amperes. Unless otherwise noted, all spatial positions presented in this paper have been normalized by the mean thruster diameter of the relevant thruster. Mean thruster diameter is defined as the average of the inner and outer discharge-channel wall diameters. The normalized axial coordinate $\mathrm{Z}$ is equal to 0 at the channel exit plane of the thruster and is positive downstream of the channel exit. The normalized radial coordinate $\mathrm{R}$ is equal to 0 at the thruster centerline and is positive towards the 3 o'clock position on the thruster face when viewing the thruster face-on.

\section{A. Thrusters and Test Matrixes}

The NASA-300M and the NASA-457Mv2 are magnetic-layer Hall thrusters designed based on the principles outlined in Manzella's dissertation work. ${ }^{14}$ Both thrusters were originally developed for high-specific-impulse missions ${ }^{7}$. The two thrusters have lens-type magnetic field topology. ${ }^{15}{ }^{16}$ Each thruster ran with a centrally-mounted hollow cathode derived from the discharge cathode for NASA's Evolutionary Xenon Thruster (NEXT). ${ }^{7}$ For the data presented in this paper, the magnetic field settings of the thruster were optimized to give a roughly symmetric shape while maximizing anode efficiency. The cathode flow fraction was maintained at $8 \%$.

The nominal operating condition of NASA-300M is $500 \mathrm{~V}, 40 \mathrm{~A}$. For this test, the $300 \mathrm{M}$ is operated at seven conditions spanning discharge voltages of 200 to $500 \mathrm{~V}$, discharge currents of 20 to $67 \mathrm{~A}$, and discharge powers of 10 and $20 \mathrm{~kW}$. The anode efficiency of this thruster, defined in Eq. (1), varies from 57 to $73 \%$ over the tested operating conditions.

$$
\eta_{\mathrm{a}}=\frac{\mathrm{T}^{2}}{2 \dot{\mathrm{m}}_{\mathrm{a}} \mathrm{I}_{\mathrm{d}} \mathrm{V}_{\mathrm{d}}}
$$


In this equation, $T$ is thrust, $\dot{\mathrm{m}}_{\mathrm{a}}$ is anode mass flow rate, $\mathrm{I}_{\mathrm{d}}$ is discharge current, and $\mathrm{V}_{\mathrm{d}}$ is discharge voltage. The boron nitride channel walls of the $300 \mathrm{M}$ are largely un-eroded for this present test. These channel walls have accumulated at most 70 hours prior to the start of the tests described in this paper.

The nominal operating condition of NASA-457Mv2 is $500 \mathrm{~V}, 100 \mathrm{~A}$. For this test, the $457 \mathrm{Mv} 2$ is operated at 14 conditions spanning discharge voltages of 200 to $500 \mathrm{~V}$, discharge currents of 40 to $100 \mathrm{~A}$, and discharge powers of 10 to $50 \mathrm{~kW}$. The anode efficiency of the $457 \mathrm{Mv} 2$ varies from 55 to $70 \%$ over the tested operating conditions.

The test matrixes of the near-field Faraday probe test were chosen to target a variety of discharge voltages in order to characterize the thrusters for both high thrust-to-power (low specific impulse) and high specific impulse operation. Many of the conditions chosen also enable constant-current and constant-power trend studies. Figure 1 shows a diagram of all operating conditions tested for the present study for both the $300 \mathrm{M}$ and the $457 \mathrm{Mv} 2$.

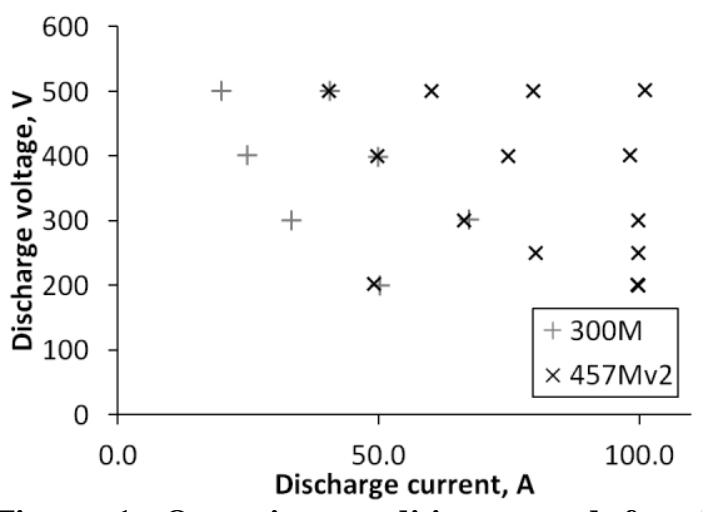

Figure 1. Operating conditions tested for this study.

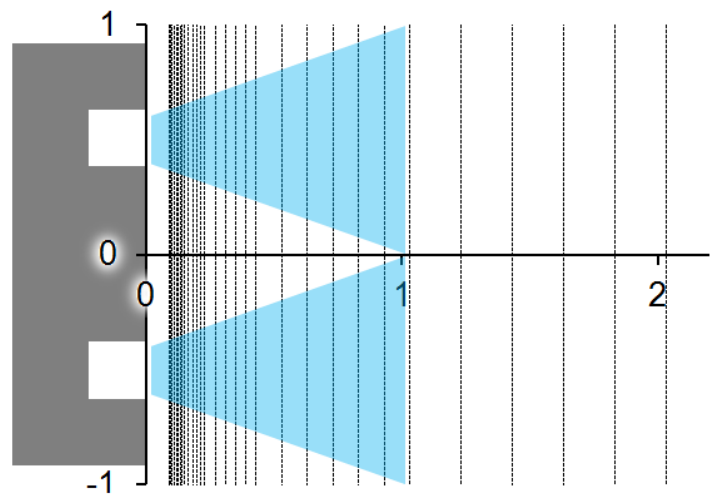

Figure 2. A diagram of the spatial resolution of radial sweeps taken for the $300 \mathrm{M}$.

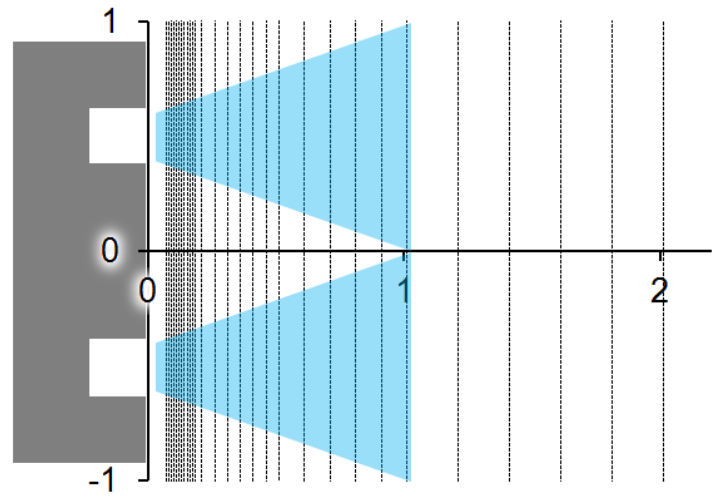

Figure 3. A diagram of the spatial resolution of radial sweeps taken for the $457 \mathrm{Mv} 2$.
To aid in the creation of the data location matrix, predicted near-field plume characteristics were drawn from a Hall2De simulation study on the NASA-300M performed by Mikellides, et al.. ${ }^{17}$ From prior tests on other Hall thrusters of similar design, some ion acceleration was expected to take place downstream of the exit plane. Thus, the axial spatial resolution of the ion current density data is highest in the region nearest the thruster channel exit. The spatial resolution decreases as the probe travels axially away from the thruster. The spacing is based on the predicted plasma density and the assumption that changes in the plasma should become more gradual as the plasma density falls. The data location matrix for the NASA$457 \mathrm{Mv} 2$ was created based on geometric scaling from that of the 300M. Figures 2 and 3 show the spatial density of radial sweeps taken for the $300 \mathrm{M}$ and $457 \mathrm{Mv} 2$, respectively.

American Institute of Aeronautics and Astronautics 


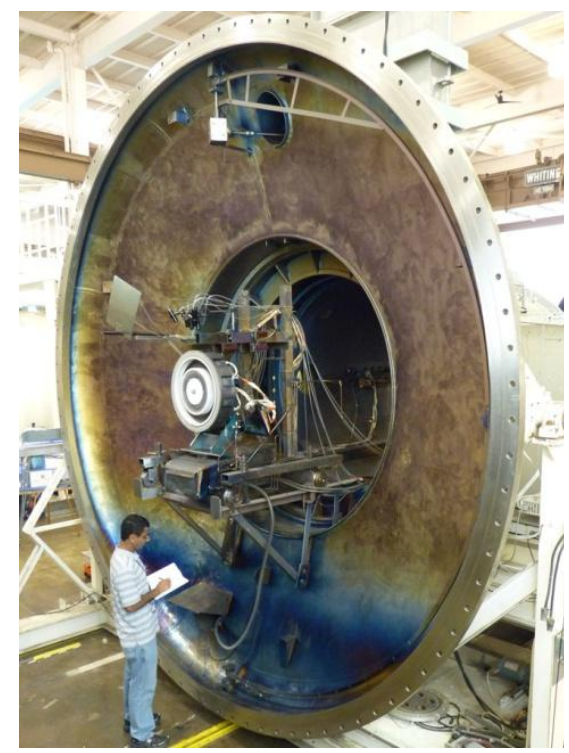

Figure 4. NASA-457Mv2 mounted for testing.

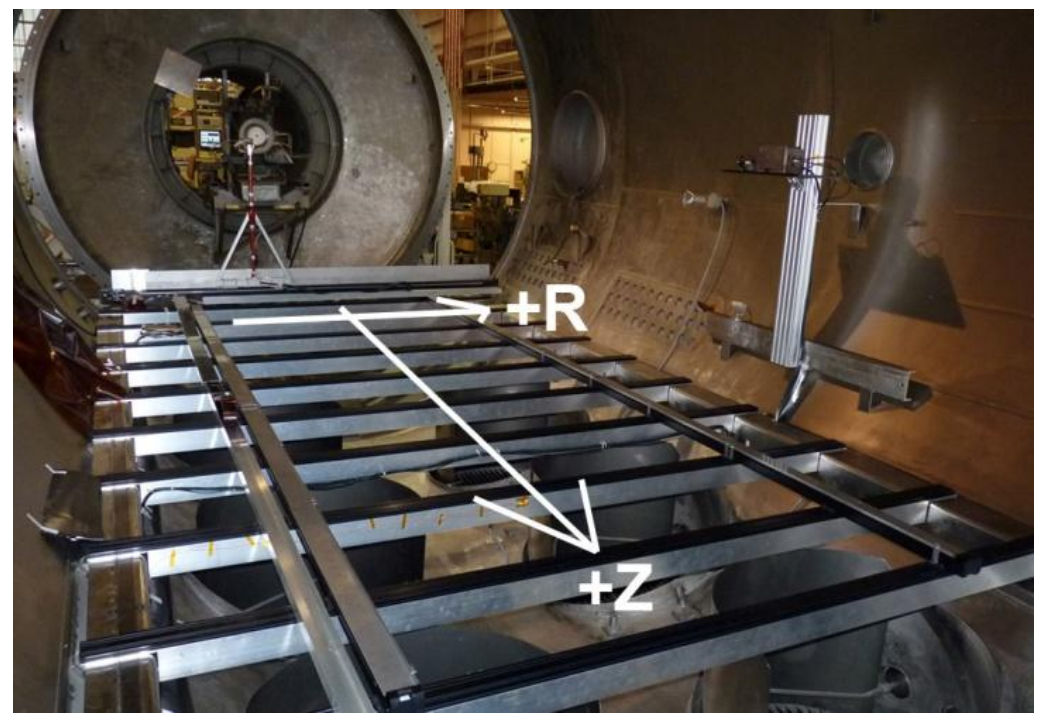

Figure 5. Photograph of the motion system in Vacuum Facility 5.

\section{B. Vacuum Facility and Motion Stages}

Testing was conducted in NASA GRC's Vacuum Facility 5. This cylindrical facility is $4.6 \mathrm{~m}$ in diameter and $18.3 \mathrm{~m}$ long and was pumped with a set of cryo-panels and 20 oil diffusion pumps. The two thrusters were each mounted on a thrust stand in the main volume of the vacuum facility to ensure low pressures near the thruster during operation. A photograph of the $457 \mathrm{Mv} 2$ mounted on the thrust stand is shown in Fig. 4. Facility pressures were monitored with five ion gauges, one of which is mounted next to the thrust stand. Facility pressure uncertainties were estimated by the manufacturer to be within $\pm 6 \%$ of reading. Pressure reading, corrected for xenon, next to the thrust stand was less than $4.0 \times 10^{-3} \mathrm{~Pa}\left(3.0 \times 10^{-5}\right.$ Torr $)$ throughout testing.

A gas feed system made of commercially available components was used to feed xenon to the thruster. A 1000sccm mass flow controller provides propellant to the anode while a $200-\mathrm{sccm}$ controller provides propellant to the cathode. Both controllers were calibrated using xenon prior to testing. Typical uncertainties reported herein were $\pm 1.0 \%$ of reading for the anode mass flow and $\pm 1.1 \%$ of reading for total mass flows.

A commercial discharge power supply was used and was capable of supplying $2000 \mathrm{~V}$ at over $100 \mathrm{~A}$ with a 5.5 $\mathrm{mF}$ output filter capacitance. A $15.3 \mathrm{mF}$ capacitor bank was connected in parallel with the power supply at the electrical feed-throughs of the vacuum facility to filter discharge current oscillations. In addition, separate commercial power supplies were used to power the cathode heater, cathode keeper, and electromagnets.

The near-field probe array, which includes the Faraday probe, was mounted onto a commercially available twoaxis belt-driven motion system. Figure 5 shows a photograph of the motion system. The radial stage was modified to operate at high speed, typically $250 \mathrm{~mm} / \mathrm{s}$, to minimize heating experienced by the probes as they pass in front of the thruster. The total radial travel of the probe array encompasses several mean-thruster-diameters worth of space in either direction from the thruster centerline. To reduce the influence of plasma oscillations on the analysis, every 50 data points in the radial direction are averaged, giving a total of $\sim 5000$ averaged data points spread evenly across the entire radial travel. The uncertainty in the axial and radial position of the system is less than $0.1 \%$ of the overall travel. The near-field probe array includes a Faraday probe, a Langmuir probe, and two emissive probes. This paper will only report on the Faraday probe measurements. The Langmuir- and emissive-probe results are reported in companion papers. ${ }^{18,19}$

Other diagnostics used during the tests include thrust stand, ${ }^{8}$ optical emission spectroscopy, ExB probes, retarding potential analyzer, and thermocouples. The results from these diagnostics will not be reported in this paper. 


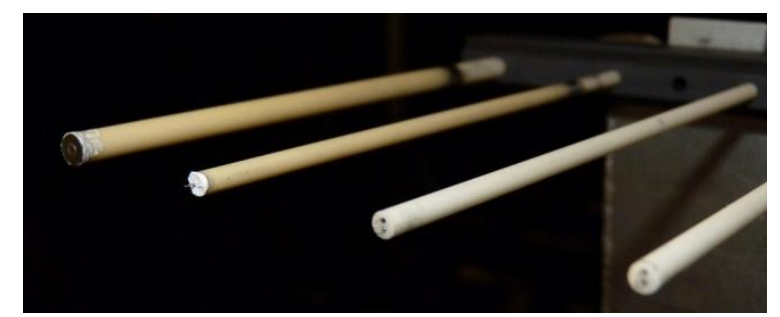

Figure 6. Probe array with Faraday probe at far left.

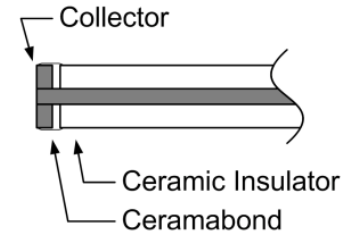

Figure 7. Diagram of the nearfield Faraday probe.

\section{Faraday Probe}

Figure 6 shows a photograph of the probe array with Faraday probe at the far left of the picture. The probes were held by a small graphite block. Graphite was selected as the material for the block to minimize back-sputtered products when passing in front of the thruster. The Faraday probe collector front surface protrudes $\sim 120 \mathrm{~mm}$ in front of the graphite block to minimize the amount of material that can perturb the plasma plume when the array passes close to the thruster exit. Each probe was spaced approximately $30 \mathrm{~mm}$ apart in the radial direction. The graphite block was mounted onto a triangular frame with a square tube as the primary vertical member. This design was chosen to minimize weight and motion-induced vibrations while maintaining structural rigidity.

Figure 7 shows a cross-sectional diagram of the Faraday probe, which was used to measure ion current density. The collector was a circular molybdenum disk with a hole punched into the center. A tungsten rod was press fitted into that hole and fitted into an alumina tube. The collector front surface area was $18.5 \mathrm{~mm}^{2}$. The alumina tube had roughly the same diameter as the collector to minimize probe footprint. Ceramabond was used to bond the collector to the alumina tube, and to cover up the sides of the collector to minimize fringe effects.

\section{Data Acquisition}

The experiment was conducted via a LabVIEW program from a dedicated data acquisition computer. The motion stages were controlled by a motion controller that received movement commands from the computer. Encoder signal from the stages were fed in a US Digital USB4 encoder controller, which reports to the computer. The signal from the Faraday probe is connected to a Faraday probe circuit box, which includes a $100-\Omega$ calibrated current shunt and an isolation amplifier. The bias voltage on the Faraday probe was varied from $-60 \mathrm{~V}$ to $-90 \mathrm{~V}$ with respect to ground via a power supply connected to the

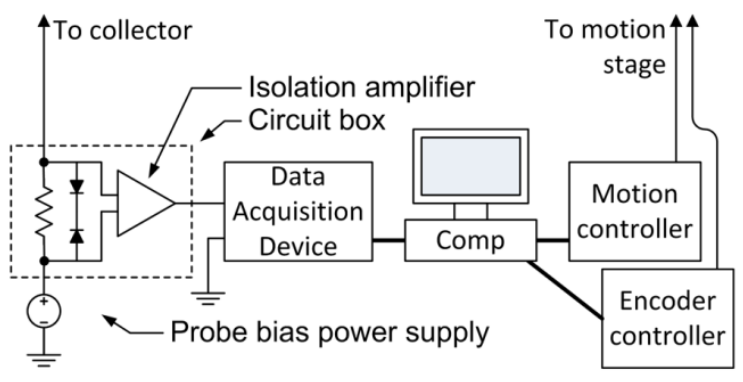

Figure 8. Electronic setup for the tests. circuit box. The bias voltage was selected based on the least negative voltage that appears to repel the majority of the electrons. The value is typically found by taking multiple Faraday probe sweeps at varying bias voltage while keeping all else constant. Despite best effort, it appears that for a small region very near the thrusters, at some of the operating conditions, the bias was not negative enough. These instances of insufficient bias did not appear to have affected the overall trends in the data and are discussed further in the uncertainty section. The isolated signal from the circuit box was fed into an NI-9205 data acquisition module attached to an NI cDAQ-9178 unit, which was controlled by the computer. Figure 8 shows a diagram of the electronic setup.

\section{Data Reduction}

\section{A. Charge-Weighted Divergence Equation for Radial Sweep}

The cosine of the momentum-weighted divergence angle characterizes the decrease in thrust due to propellant particles that have radial velocity components. Due to difficulties in measuring momentum-weighted divergence angle, it is common practice in the Hall thruster community to measure the charge-weighted divergence angle instead. If the plume is axisymmetric, the charge-state ratios are constant, and the average particle velocity is constant throughout the measurement domain then the aforementioned angles are equal. ${ }^{20}$ For a radially-swept probe where the surface normal vector of the collection area is always pointed along the thruster firing axis, the measured current density is the axial component of the local ion current density. Equation (2) can be used to calculate the charge-weighted divergence angle. ${ }^{21}$ 


$$
<\cos \delta>_{\mathrm{j}}=\frac{2 \pi \int_{0}^{\infty} \mathrm{j}_{\mathrm{z}}(\mathrm{r}) \cos \theta \mathrm{rdr}}{2 \pi \int_{0}^{\infty} \mathrm{j}_{\mathrm{z}}(\mathrm{r}) \mathrm{rdr}}, \cos \theta=\frac{\mathrm{z}_{\mathrm{p}}}{\sqrt{\mathrm{r}^{2}+\mathrm{z}_{\mathrm{p}}^{2}}}
$$

In this equation, $\delta$ is the charged-weighted divergence angle, $\theta$ is the polar angle and is equal to $0^{\circ}$ for particles with purely axial velocity, and $j_{z}(r)$ is the axial ion current density as a function of the radial coordinate $r . z_{p}$ is the axial distance from the probe to the thruster and is constant for a radial sweep. Note the denominator is equal to the total ion current.

One issue with analyzing the results of radial Faraday-probe sweeps in the near-field plume is that the limits of integration must be picked carefully. Although Eq. (2) calls for integration from 0 to $\infty$, this is physically impossible and undesirable. Once the probe leaves the vicinity of the thruster in the near-field, it will measure mostly chargeexchanged and background ions that are not a part of the beam. It is also likely that the measurement system will see some noise and/or systematic offset. Due to the nature of the integral in Eq. (2), non-beam ions and noise will quickly begin to dominate if the limits of integration are taken too far in the radial direction. Previous studies have shown that the results of the integral are very sensitive to the choice of integration limits. ${ }^{21,22}$

Another issue for near-field Faraday-probe sweeping is the location of the point of origin. For Faraday probe sweeps in the far-field, the Hall thruster can often be assumed to be a point source with the origin at the intersection between the thruster centerline and the thruster channel exit plane. ${ }^{20}$ For near-field Faraday probe sweeps, there is no obvious point of origin from which to calculated plume divergence. However, over the course of trying various analytical methods on the present data, an interesting approach was found that appears promising. The next two sections will discuss some possible limits of integration and a previously untried method for locating an effective point of origin, respectively.

\section{B. Limits of Integration}

For a set of radially-swept data, as one goes further and further in the radial direction, there will come a point when the signal is dominated by undesirable effects like non-beam ions, noise, and electronic offsets. If the limits of integration are set too large, the said undesirable effects will typically cause one to overestimate the total beam current and the divergence angle. If the limits of integration are set too small, one may not capture enough beam ions and will underestimate the divergence angle.

Previous work by Reid showed that if one integrates from thruster centerline all the way to the edge of available data, the integrated total beam current often exceeded the discharge current, and the result is therefore unphysical. ${ }^{12}$ $\mathrm{He}$ also found that the profile of the ion current density prior to merging with the cathode plume and the plume from the other side of the thruster greatly resembles a Gaussian distribution. Figure 9 shows one such ion current density profile from the current tests along with a best-fit Gaussian distribution. Reid proposed the use of 1/e thresholdbased limits based on laser beam physics (ideal laser beam profile is a Gaussian distribution). ${ }^{12}$ For the thresholdbased approach, the limits of integration are set to the two points on each side of the Gaussian distribution where the intensity has dropped to some fraction (1/e in this case) of the peak intensity. Note that the "e" in 1/e stands for the natural exponent, also known as the Euler number, and has a value of $\sim 2.71828$. This "e" is not to be confused with

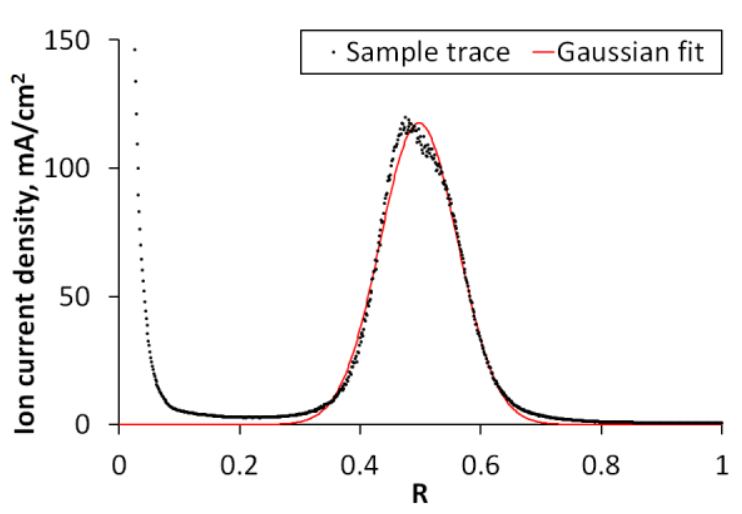

Figure 9. Gaussian fit to an example ion current density profile found in front of one side of the thruster. the elementary charge.

The threshold-based approach generates two limit points for each side of the thruster plume. These two points will be referred to as the "inner" integration limit and the "outer" integration limit. The radial location of inner integration limit will be between the thruster centerline the center of the discharge-channel plume. The radial location of the outer integration limit will be greater than the center of the discharge-channel plume. In cases where the inner side (the side nearer to the thruster centerline) of the plume from the channel has begun to merge with the cathode plume, the local minimum is selected as the inner integration limit. In cases where this local minimum does not exist, the plumes from the two sides are considered to have started merging and the inner integration limit is set to the thruster centerline.

6

American Institute of Aeronautics and Astronautics 
Figures 10 to 12 show three different types of example traces and how the threshold-based limits are determined for each type of trace. Although $1 / \mathrm{e}$ as a threshold value gave reasonable results for Reid's experiment, there is no

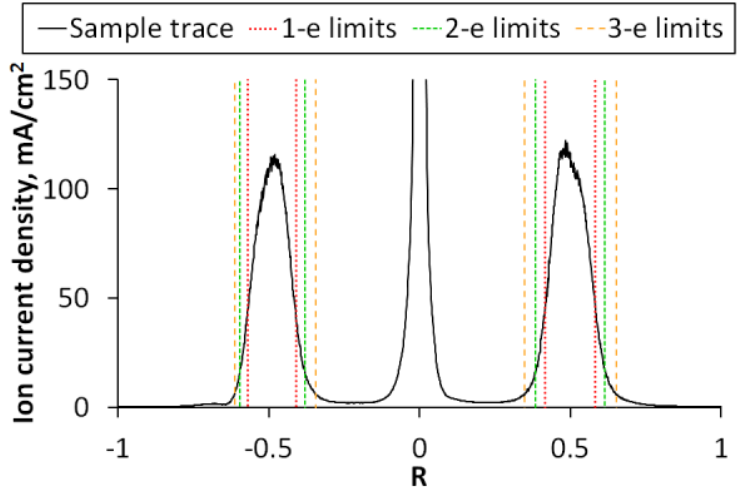

Figure 10. An example of ion current density profile from an axial location where no plume merging has occurred yet $(457 \mathrm{Mv} 2,300 \mathrm{~V}, 100 \mathrm{~A}$, $\mathbf{Z}=\mathbf{0 . 0 9 6 )}$. Associated limits are plotted.

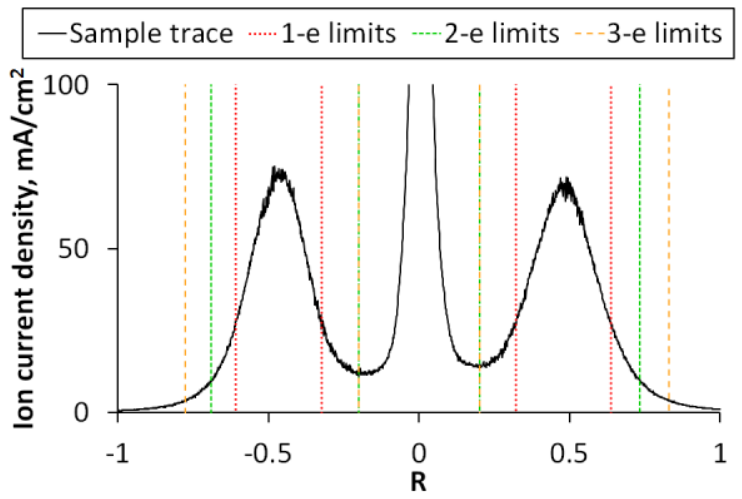

Figure 11. An example of ion current density profile from an axial location where channel plume began merging with cathode plume $(457 \mathrm{Mv} 2,300 \mathrm{~V}, 100 \mathrm{~A}, \mathrm{Z}=\mathbf{0 . 3 6 6})$. Associated limits are plotted.

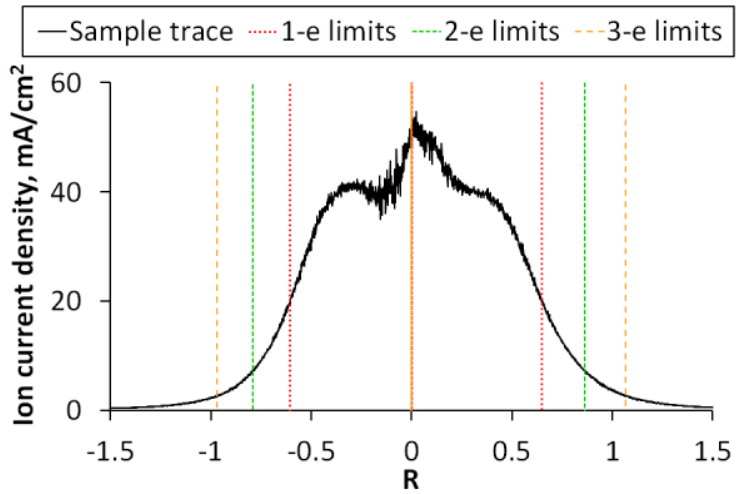

Figure 12. An example of ion current density profile from an axial location where channel plumes from the two sides are merging (457Mv2, $300 \mathrm{~V}, 100 \mathrm{~A}, \mathbf{Z}=\mathbf{0 . 9 1 5}$ ). Associated limits are plotted. definitive evidence that the corresponding limits captured enough beam ions. As such, $1 / \mathrm{e}^{2}$ and $1 / \mathrm{e}^{3}$ were also tried as threshold values. For simplicity, the threshold-based integration limits with threshold values of $1 / \mathrm{e}, 1 / \mathrm{e}^{2}$, and $1 / \mathrm{e}^{3}$ will be referred to as the 1-e, 2-e, and 3-e limits, respectively; the corresponding numeric values of these thresholds are $36.8 \%, 13.5 \%$, and $5.0 \%$, respectively.

Total ion current integration was performed with the three sets of integration limits. Figure 13 shows an example of plotting the total ion current as a function of the normalized axial coordinate. After processing many operating conditions across both thrusters, it was found that the value of the integrated ion current is typically stable between $\mathrm{Z}=0.2$ and 0.75 . The only exception was $200-\mathrm{V}$ and $250-\mathrm{V}$ operation on both thrusters where the stable range is between $Z=0.2$ and 0.5 . Closer inspection of the individual ion current density profiles revealed that this region corresponds to the part of the plume just after the acceleration zone and before the plume from the two sides began merging. For, the $200-\mathrm{V}$ and $250-\mathrm{V}$ data, the plume merges noticeably further upstream, which is why the downstream limit on $\mathrm{Z}$ for the stable range was 0.5 instead of 0.75 . Note that this downstream limit is a rough measure of where plume from the two sides of the thruster starts to merge. While the downstream limit is further downstream for some conditions than for others it is no further upstream than 0.5 for $200-\mathrm{V}$ and $250-\mathrm{V}$ data and no further upstream than 0.75 for all other data. This downstream limit will play an important role in determining the data that will be used to find the point of origin.

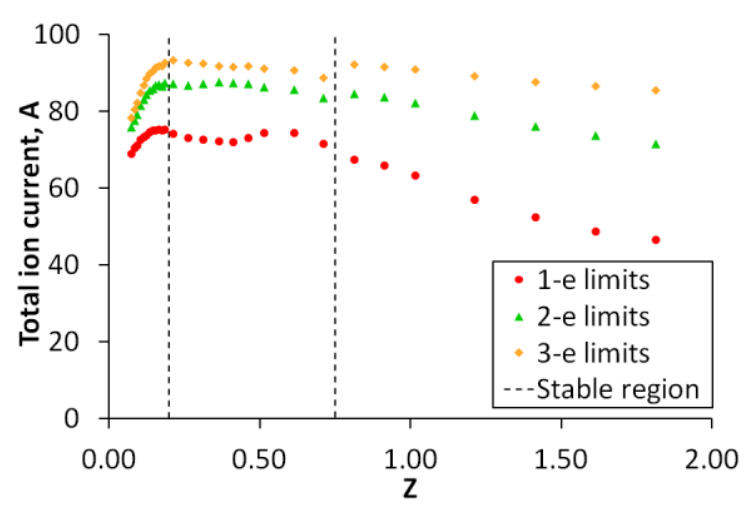

Figure 13. An example plot of the total ion current as a function of normalized axial coordinate $(457 \mathrm{Mv} 2,300 \mathrm{~V}, 100 \mathrm{~A})$. 


\section{Point of Origin for Divergence Calculation}

While total ion current can be calculated using only the limits of integration, a point or origin is also need to calculate divergence angle. Prior works have taken the channel center at channel exit plane as the local point of origin for near-field plume on each side of the thruster. ${ }^{12}{ }^{13}$ However, this choice of origin was not based on any known Hall thruster physics and was chosen mainly for convenience. In the course of studying the behavior of the total ion current as a function of different integration limits, a novel approach with physical basis was discovered.

The premise of the new approach is based on an assumption that the near-field plume from the discharge channels can be modeled as a Gaussian beam. This assumption is typically valid within $0.2<\mathrm{Z}<0.75(0.2<\mathrm{Z}<0.5$ for $200-\mathrm{V}$ and $250-\mathrm{V}$ operation). If the assumption holds true, one can construct beam paths, much like laser rays, using the positions of the 1-e, 2-e, and 3-e limits in the near-field, to follow the spatial evolution of the beam. And if the near-field plume behaves like a Gaussian beam emanating from a single point of origin, the three rays traced out in such a fashion will intersect at one point. That point is the effective point of origin for the near-field plume. Note that the point of origin only appears as a point when viewing a 2D cross section of the Hall thruster. In a 3D axisymmetric environment, the point of origin will appear as a ring of origin, and the near-field plume is Gaussian in the radial direction and uniform in the azimuthal direction. However, for the sake of simplicity, discussions henceforth will treat the point of origin as a point in a 2D slice of the Hall thruster with the understanding that it is a ring in $3 \mathrm{D}$.

Figure 14 shows the ion current density flooded-contour plot for the NASA-457Mv2 operating at $300 \mathrm{~V}$ and 100 A. Overlaid on top of the contour plot in red, green, and orange dashed lines are the 1-e, 2-e, and 3-e limits of integration, respectively, based on the threshold-based approach mentioned in the previous section. Also overlaid on the contour in red, green, and orange solid lines are linear curve fits performed on the locations of the 1-e, 2-e, and 3 -e integration limits, respectively, within the range $0.2<Z<0.75$. Since there are three lines for each side of the Hall thruster, three intercepts can be calculated. A red circle is drawn for each of those intercepts and a larger black circle is drawn for the average of the three intercepts. For Fig. 14, the red circles lie so closely on top of one another that they appear as two red blobs inside of the corresponding black circles. Across both thrusters and all operating conditions, the three intercepts on each side are typically within \pm 0.03 mean thruster diameter of the average. The one notable exception was found when analyzing the $300 \mathrm{M}, 400 \mathrm{~V}, 25$ A data where the intercepts were within \pm 0.1 mean thruster diameter of the average. Generally, the axial location of the average of the intercepts lie deep within the channel, sometimes further upstream than the anode front surface. The radial location of the average of the

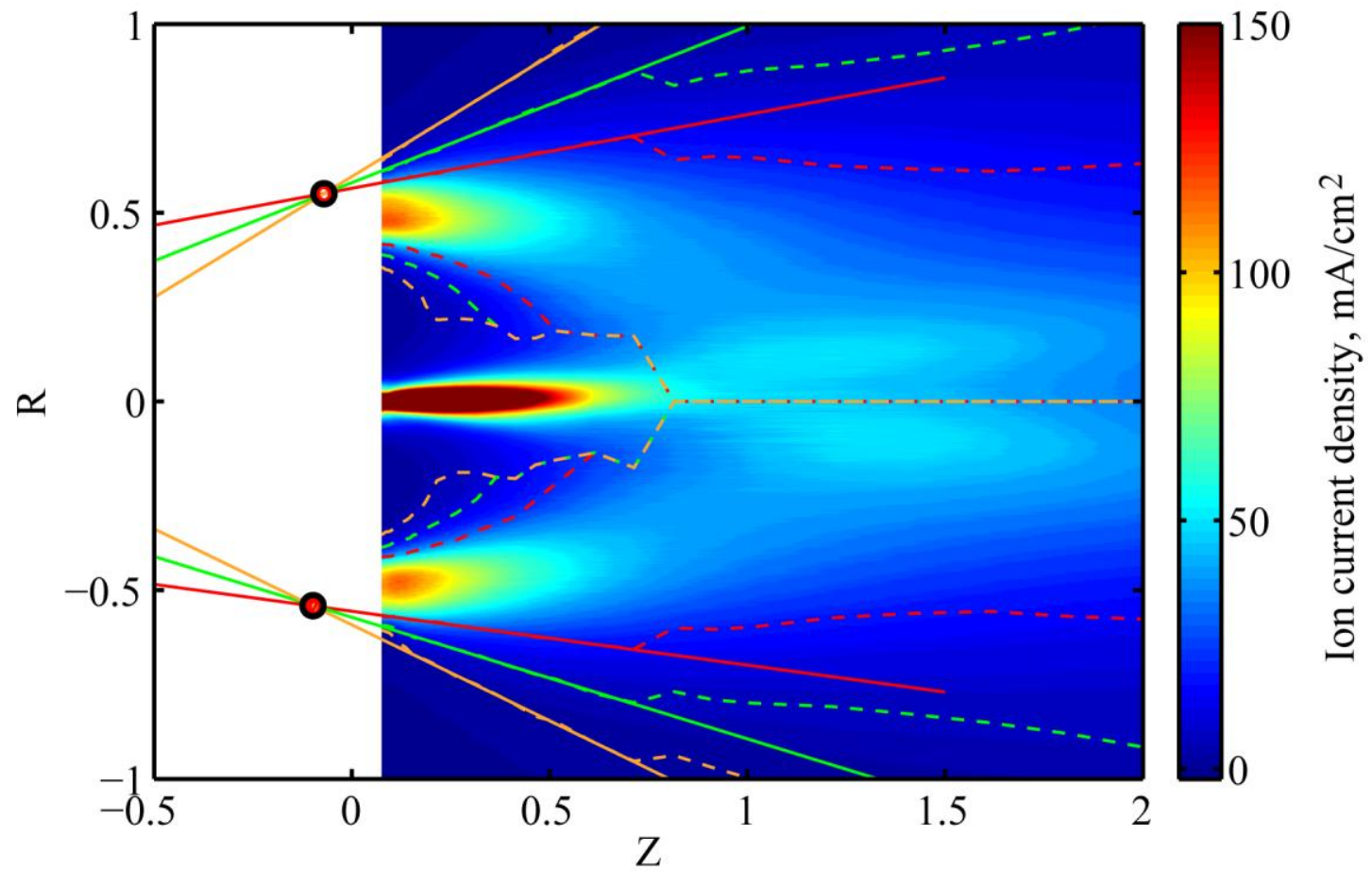

Figure 14. Ion current density flooded-contour plot for the NASA-457Mv2 operating at $300 \mathrm{~V}$ and $100 \mathrm{~A}$ with integration limits and divergence analysis curve fits overlaid on top.

8

American Institute of Aeronautics and Astronautics 
intercepts is also typically more towards the outer channel wall than the inner channel wall. Physical implications for these trends will be discussed in section IV.B.

Given how well the three lines formed by the 1-e, 2-e, and 3-e limits converge for most tested conditions, the average of the intercepts is taken to be the point of origin for the divergence calculation. For each operating condition, Eq. (2) was tried with all three integration limits. Note that the $r^{2}$ term in the calculation for $\cos \theta$ must be replaced with $\left(r-r_{0}\right)^{2}$ where $r_{0}$ is the radial coordinate of the point of origin.

As previously mentioned, the threshold-based approach to finding limits of integration generates four limit points, two on the $+\mathrm{R}$ side and two on the $-\mathrm{R}$ side. For each side of the thruster plume, the ion current density is integrated from the corresponding inner integration limit to the outer integration limit. The two total ion currents (one calculated from each side of the plume) are then averaged to produce the total ion current that will be shown in the results section.

For divergence calculation, the integration limits are selected slightly differently. Instead of integrating from the inner integration limit to the outer integration limit, it is integrated from the radial position of the point of origin to the outer integration limit. This is done because the plume shape from the inner integration limit up to the radial position of the point of origin is difficult to analyze, owing to the influence of the cathode plume. As a result of this choice of integration limits for divergence calculation, the reported divergence angle is strictly of the outer side of the discharge-channel plume in the near-field. This "outer-side" divergence angle is only representative of the overall divergence angle if, on the average, the near-field discharge-channel plume is pointed purely in the axial direction. Examination of the calculated outer-side divergence angle in a later section will show that there is

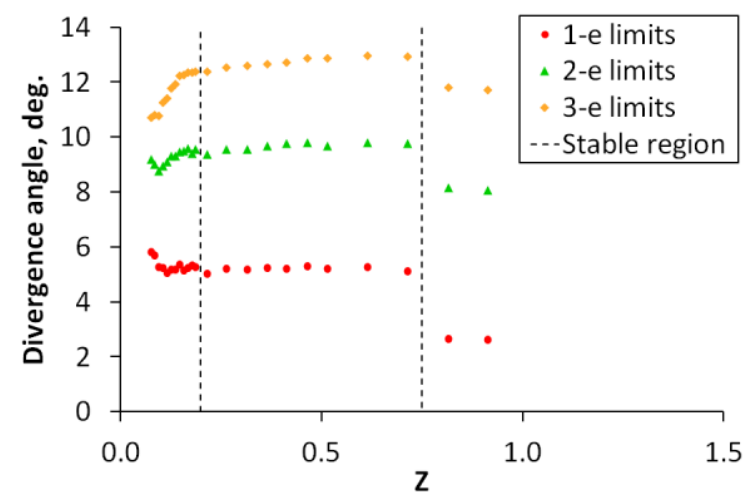

Figure 15. An example plot of the outer-side divergence angle as a function of normalized axial coordinate $(457 \mathrm{Mv} 2,300 \mathrm{~V}, 100 \mathrm{~A})$. evidence the near-field discharge-channel plume is not pointed purely in the axial direction. Figure 15 shows an example of plotting the outer-side divergence angle as a function of normalized axial coordinate. The angle value is mostly constant within $0.2<\mathrm{Z}<0.75(0.2<\mathrm{Z}<0.5$ for $200-\mathrm{V}$ and $250-\mathrm{V}$ operation).

\section{Uncertainty Analysis}

There were three main sources of uncertainty for the ion current density measurements. First, the electronics circuit drifted over the course of the tests, the associated uncertainty in the current density, based on pre-test and post-test calibration, is $\pm 2 \%$ or $\pm 0.002 \mathrm{~mA} / \mathrm{cm}^{2}$, whichever is greater.

Second, the effective collection area expands depending on applied bias voltage and the local plasma density. Following a sheath calculation procedure from a prior experiment, ${ }^{13}$ simple calculations based on sheath physics were carried out and the worst-case scenario for the data presented in this paper is $\sim 5 \%$ collection area increase. To keep the uncertainty estimate conservative, we doubled the value associated with the aforementioned effect to $\sim 10 \%$. Since the area appears in the denominator of the ion current density calculation, the uncertainty associated with area expansion is $+0 \% /-10 \%$. The total uncertainty from uncertainty sources one and two is $+2 \% /-10 \%$ or $\pm 0.002 \mathrm{~mA} / \mathrm{cm}^{2}$, whichever is greater.

Third, there were some regions of the interrogated domain where the floating potential is so negative that even a $-90 \mathrm{~V}$ bias is insufficient to repel all electrons. These regions tend to be small and away from the main plasma plume. Figure 16 shows one instance where the effect of insufficient negative bias can be discerned in the ion current density profile as negative current density. Comparing Fig. 16 to Fig. 10, both of which shows data from the same operating condition but spaced 0.02 mean thruster diameter apart, we see that the strongly negative floating potential at $\mathrm{Z}=0.076$ quickly becomes less negative as one travels downstream. Figure 17 shows a flooded contour map of the floating potential with respect to the facility ground for

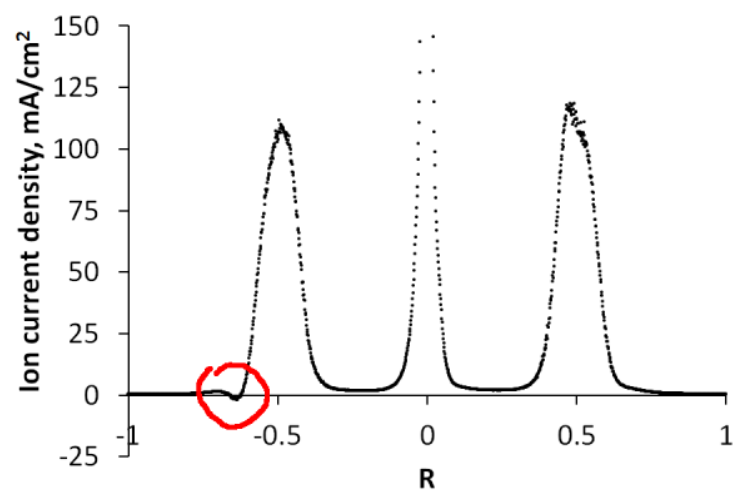

Figure 16. An example of the effect of insufficient bias voltage $(457 \mathrm{Mv} 2,300 \mathrm{~V}, 100 \mathrm{~A}, \mathrm{Z}=\mathbf{0 . 0 7 6})$. Affected region circled in red. 
$457 \mathrm{Mv} 2$ operating at $300 \mathrm{~V}, 100 \mathrm{~A}$. The region of strongly negative floating potential is circled. Floating potential was measured via a Langmuir probe in the probe array and is described in a companion paper. ${ }^{19}$

While an even greater negative bias can potentially remove these regions of negative current density, it will also cause a greater sheath expansion effect. No attempt was made to determine a proper trade-off between less negative-currentdensity data and less sheath expansion effect. Instead, we argue that the influence of this negative-current-density region is low enough and the size of the region small enough as to not affect the overall trends in the data.

The uncertainty in the total ion current and the divergence angle is difficult to quantify. Indeed, one of the goals of this paper is to study how different integration limits can influence the calculation of those two quantities. For this reason, the uncertainties in the total ion current and divergence angle due to the choice of integration limits is left un-assigned. The total ion current also inherits uncertainties from the ion current density measurement and the radial position measurement. Since uncertainty in the radial position is negligible, total ion current inherits an amount of uncertainty roughly equal to that assigned to the ion current density.

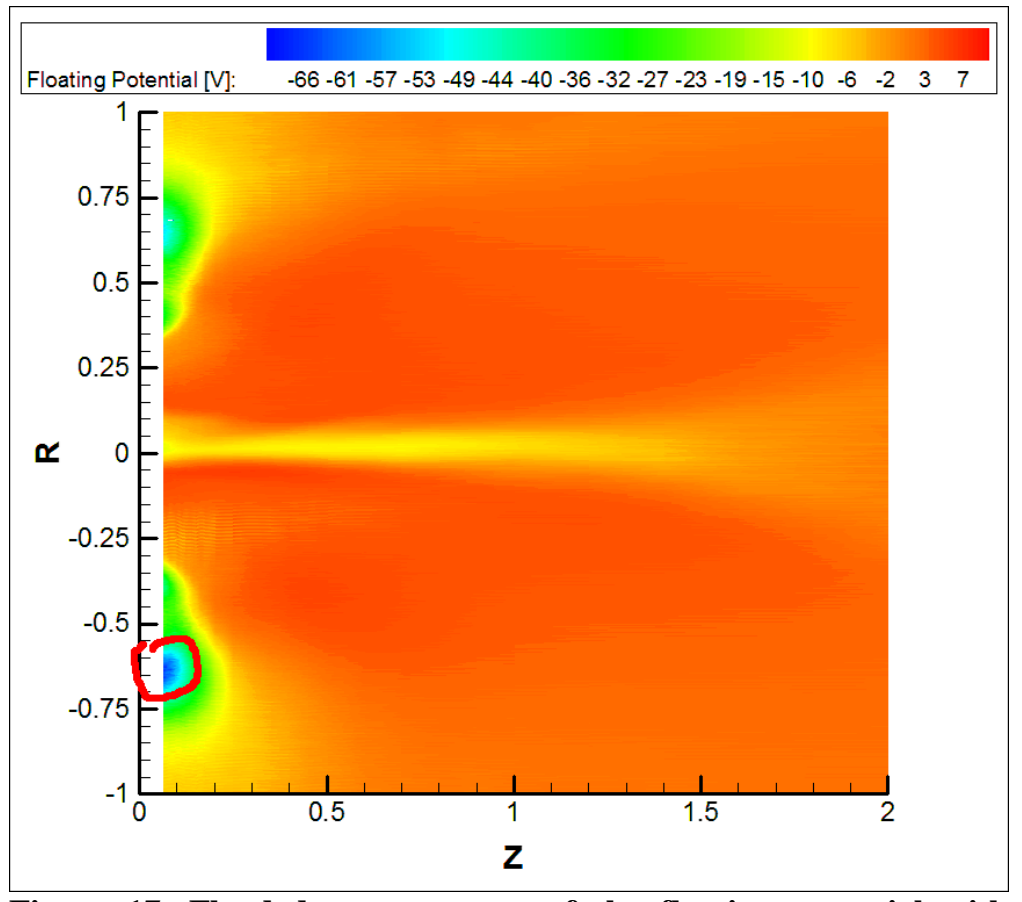

Figure 17. Flooded contour map of the floating potential with respect to the facility ground for the NASA-457Mv2 operating at $300 \mathrm{~V}, 100$ A. Region of strongly negative floating potential is circled in red. 


\section{Results}

\section{A. Ion Current Density Profiles and Flooded Contours}

Due to the large number of ion current density profiles measured, only a select few that is representative of the whole set is shown in this paper. Figures 18 and 19 show ion current density profiles from the NASA-300M operating at $200 \mathrm{~V}$ and $500 \mathrm{~V}$, respectively. Figures 20 and 21 show ion current density profiles from the NASA$457 \mathrm{Mv} 2$ operating at $200 \mathrm{~V}$ and $500 \mathrm{~V}$, respectively. Each plot shows 4 ion current density profiles taken from near the channel exit plane, $Z=0.5, Z=1$, and $Z=2$. Comparing the $200-V$ traces to the $500-V$ traces for each thruster, we see that the merging of the plume occurs much further upstream for operation at lower discharge voltage than for higher discharge voltage. Generally, the discharge-channel plume will have started interacting with the cathode plume to some degree by $Z=0.5$, and the plume from the two sides of the thruster will be interacting by $Z=1$. By $Z$ $=2$, the overall plume has more or less merged into a single profile. These physical phenomena naturally divide the plasma plume into different regions. For example, one can define the region upstream of major plume merging as the near-field (for 500-V operation, this region is $\mathrm{Z}<0.5$ ). Brown recommends that far-field Faraday probe data be taken at least 5 mean thruster diameters away based on studies of divergence angle as a function of the distance between the far-field probe and the thruster. ${ }^{20}$ Thus if one defines $\mathrm{Z}>5$ as farfield, $\sim 0.5<\mathrm{Z}<5$ can be defined as the transitional region.

The plasma structures in the transitional region appear to be very complicated. While similar shapes are seen in the plume between the two thrusters and various operating conditions, there is also some degree of variation in the shapes. Figures 22 and 23 shows flooded contours of the ion current density for the $300 \mathrm{M}$ operating at $200 \mathrm{~V}$ and $500 \mathrm{~V}$, respectively, to aid the visualization of plasma structures in the transitional region.

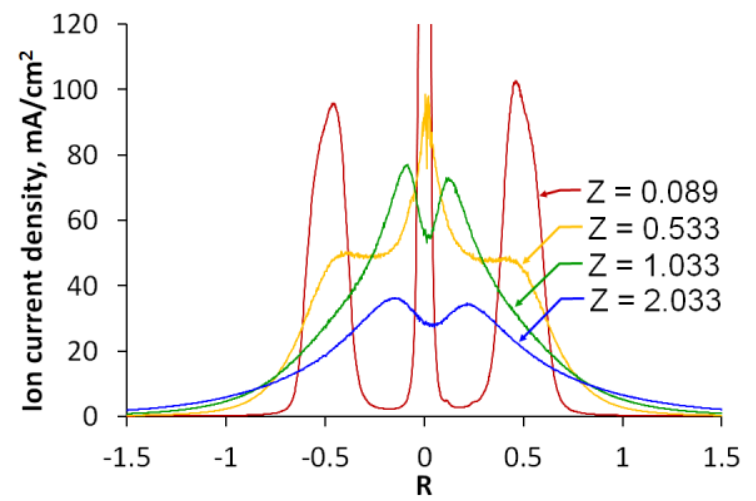

Figure 18. Ion current density profiles for $300 \mathrm{M}$ operating at $200 \mathrm{~V}, 50 \mathrm{~A}$.

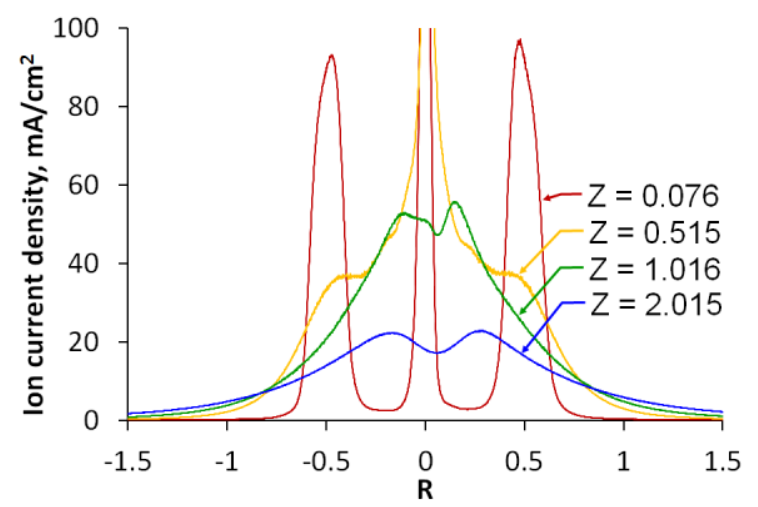

Figure 20. Ion current density profiles for $457 \mathrm{Mv} 2$ operating at $200 \mathrm{~V}, 100 \mathrm{~A}$.

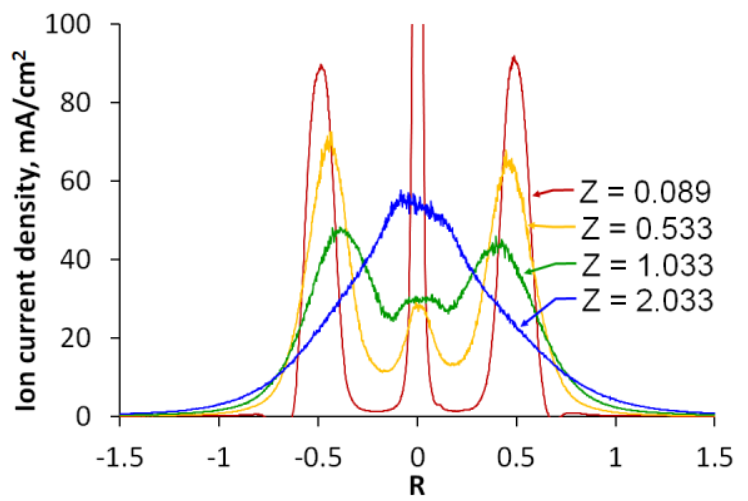

Figure 19. Ion current density profiles for $300 \mathrm{M}$ operating at $500 \mathrm{~V}, 40 \mathrm{~A}$.

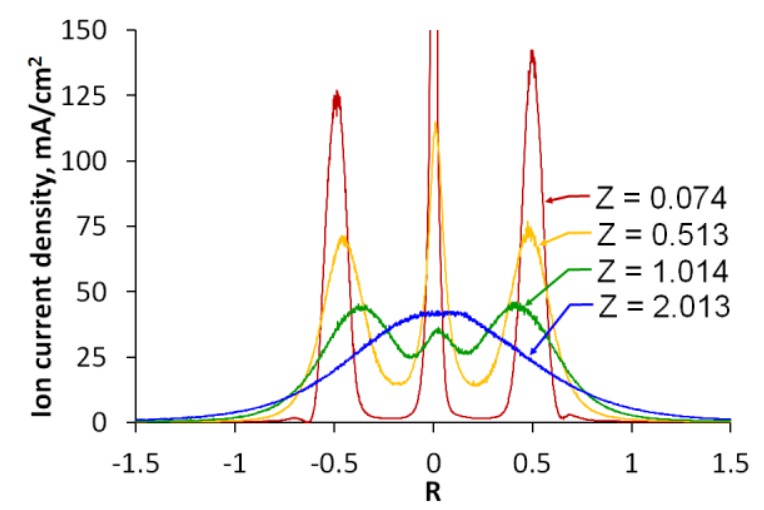

Figure 21. Ion current density profiles for $457 \mathrm{Mv} 2$ operating at $500 \mathrm{~V}, 101 \mathrm{~A}$. 


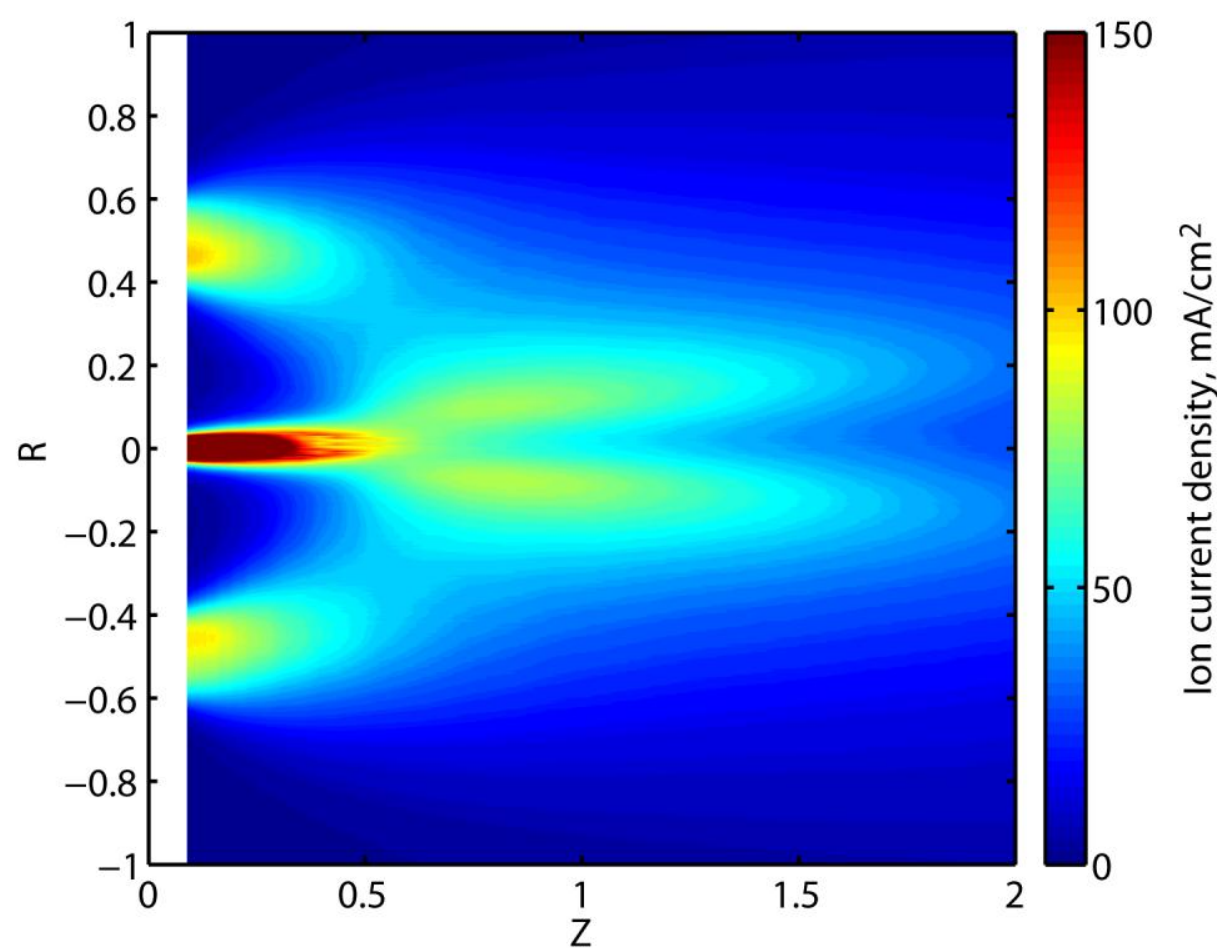

Figure 22. Flooded contour of ion current density for the $300 \mathrm{M}$ operating at $200 \mathrm{~V}, 50 \mathrm{~A}$.

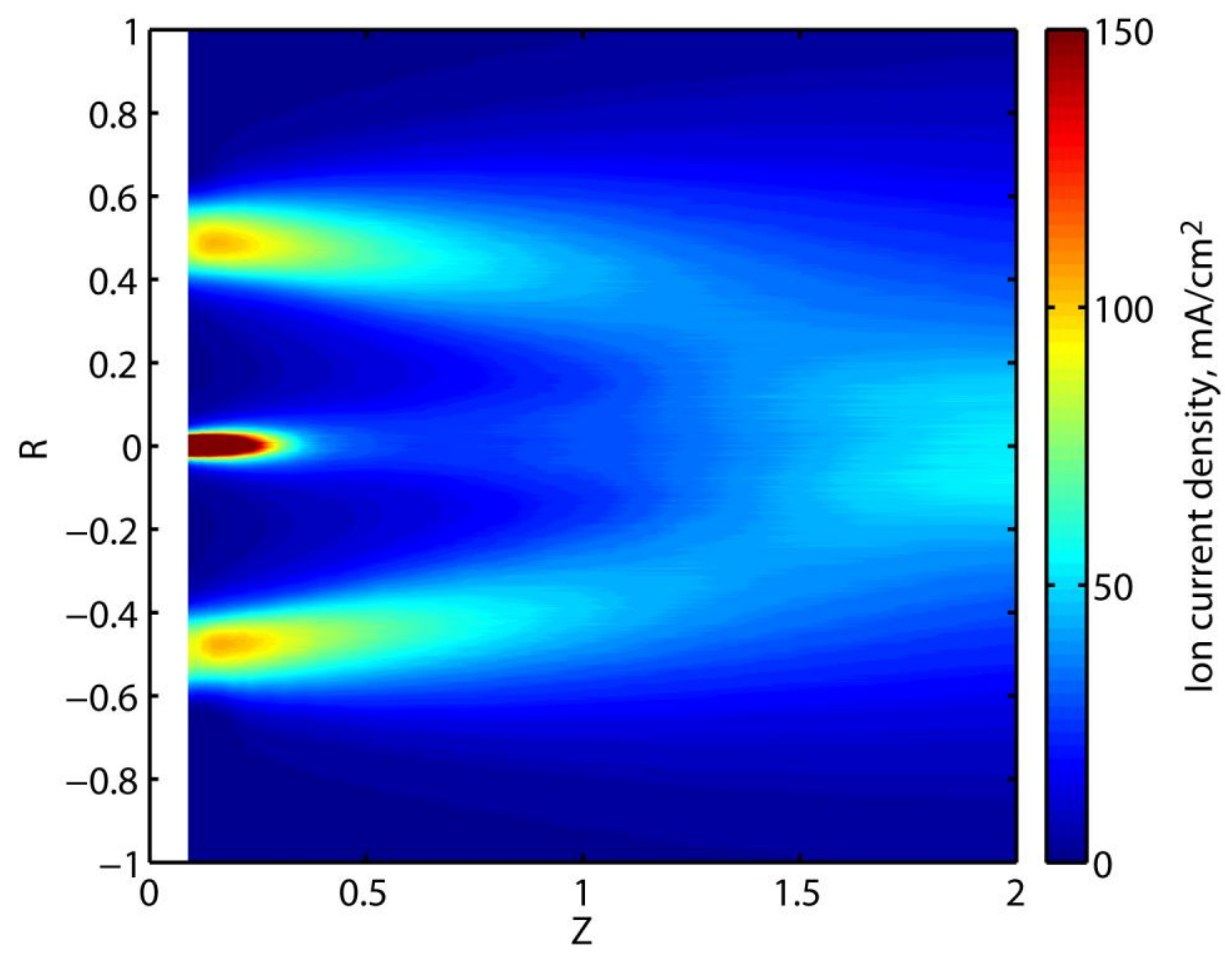

Figure 23. Flooded contour of ion current density for the 300M operating at $500 \mathrm{~V}, 40 \mathrm{~A}$. 
Figures 22 and 23 show two extremes of what was observed over the course of the experiments. At higher discharge voltages, the shape of the ion current density contour generally resembles a trident, with two prongs from the discharge plume and one prong from the cathode. At lower discharge voltages, the shape looks more complicated, somewhat resembling the front of a triceratops. The discharge plume makes up the front legs of the triceratops, the cathode plume makes up the front horn and the two more horns jut out from the top. A variety of shapes in between these two extremes were also observed. There is also the possibility that the "trident" plume is actually an elongated version of the "triceratops" plume. That is to say if you stretch out the "triceratops" plume in the axial direction and chop it off at the $\mathrm{Z}=2$ point, the shape will look like a "trident". However, there is also a possibility that the "trident" versus "triceratops" indicate two different modes of operation (for example, the discharge plume may couple to the cathode differently in the two modes). Evidence for this can be found when comparing the flooded contour for the 457Mv2 between $200-\mathrm{V}, 49-\mathrm{A}$ and $200-\mathrm{V}, 100-\mathrm{A}$ operation, which are shown in Figs. 30 and 31, respectively. Since the discharge voltage was the same for the two conditions, one might expect the near-field plasma structure to be similar except the 100-A condition would have twice the ion current density at any given location compared to the 49-A condition. Instead, the 200-V, 49-A condition exhibit a "trident" plume and the 200-V, 100-A condition exhibit a "triceratops" plume.

Additional flooded contours for ion current density are shown in the appendix.

\section{B. Total Ion Current and Divergence Angle}

Total ion current and divergence angle were calculated based on the methodology described in the data reduction section. For each operating condition, calculations were carried out for each of the 1-e, 2-e, and 3-e integration limits. As mentioned in the data reduction section (Section III.C), the reported divergence angle is calculated from the radial position of the point of origin up to the outer integration limit. Thus, the reported angle is strictly an outerside divergence angle.

Table 1. Summary of total ion current and outer-side divergence angle analysis.

\begin{tabular}{|c|c|c|c|c|c|c|c|c|c|c|c|c|}
\hline \multirow[b]{2}{*}{ 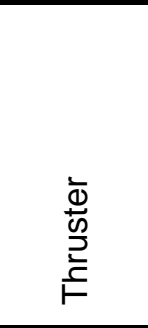 } & \multirow{2}{*}{ 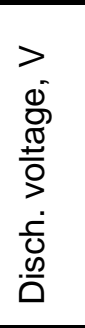 } & \multirow{2}{*}{ 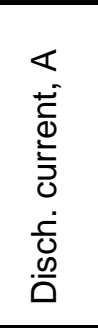 } & \multirow{2}{*}{ 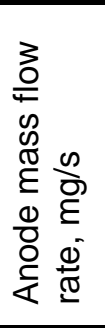 } & \multirow{2}{*}{$\begin{array}{l}> \\
0 \\
.00 \\
0 \\
0 \\
0 \\
0 \\
0 \\
0\end{array}$} & \multicolumn{2}{|c|}{$\begin{array}{l}\text { Total ion } \\
\text { current, } A\end{array}$} & \multicolumn{2}{|c|}{$\begin{array}{l}\text { Outer-side } \\
\text { divergence } \\
\text { angle, deg. }\end{array}$} & \multicolumn{2}{|c|}{$\begin{array}{l}\text { Point of } \\
\text { origin } \\
\text { (+R side) }\end{array}$} & \multicolumn{2}{|c|}{$\begin{array}{l}\text { Point of } \\
\text { origin } \\
\text { (-R side) }\end{array}$} \\
\hline & & & & & $\begin{array}{c}1-e \\
\text { limits }\end{array}$ & $\begin{array}{l}2-e \\
\text { limits }\end{array}$ & $\begin{array}{c}1-e \\
\text { limits }\end{array}$ & $\begin{array}{l}2-e \\
\text { limits }\end{array}$ & $Z_{c h}$ & $\mathrm{R}_{\mathrm{ch}}$ & $Z_{c h}$ & $\mathrm{R}_{\mathrm{ch}}$ \\
\hline \multirow{8}{*}{$300 \mathrm{M}$} & 200 & 50.3 & 39.9 & -60 & 37.2 & 42.7 & 6.3 & 12.4 & -0.30 & 0.39 & -0.28 & -0.35 \\
\hline & 300 & 33.3 & 32.3 & -60 & 22.6 & 27.6 & 1.9 & 4.7 & -1.29 & 0.20 & -1.12 & -0.24 \\
\hline & 301 & 67.3 & 52.2 & -60 & 45.0 & 52.8 & 3.6 & 9.3 & -0.33 & 0.46 & -0.28 & -0.43 \\
\hline & 401 & 24.9 & 25.2 & -60 & 17.2 & 20.9 & 2.0 & 4.9 & -1.28 & 0.20 & -1.07 & -0.25 \\
\hline & 399 & 50.0 & 43.8 & -60 & 33.9 & 40.9 & 1.8 & 4.7 & -1.03 & 0.23 & -1.01 & -0.24 \\
\hline & 501 & 19.9 & 20.7 & -60 & 14.4 & 17.1 & 2.9 & 5.7 & -1.10 & 0.16 & -0.89 & -0.22 \\
\hline & 501 & 40.6 & 37.4 & -60 & 28.6 & 33.8 & 2.9 & 5.8 & -1.13 & 0.22 & -0.73 & -0.27 \\
\hline & 202 & & $\overline{4} 6 . \overline{1}$ & $-\overline{-60}$ & & $\overline{3} 8 . \overline{3}$ & & $7 . \overline{3}$ & $-\overline{0.91}$ & $0 . \overline{10}$ & $-\overline{0} \overline{7} \overline{9}$ & -0.20 \\
\hline \multirow{13}{*}{ 457Mv2 } & 200 & 99.8 & 77.8 & -60 & 71.0 & 82.1 & 8.1 & 14.9 & -0.24 & 0.43 & -0.13 & -0.42 \\
\hline & 250 & 80.2 & 66.4 & -60 & 54.8 & 66.4 & 4.7 & 9.2 & -0.63 & 0.22 & -0.53 & -0.33 \\
\hline & 250 & 99.8 & 76.7 & -60 & 66.1 & 78.7 & 4.8 & 10.2 & -0.57 & 0.38 & -0.42 & -0.47 \\
\hline & 301 & 66.4 & 59.7 & -60 & 44.1 & 54.3 & 3.5 & 6.1 & -1.16 & 0.07 & -1.04 & -0.13 \\
\hline & 300 & 99.8 & 79.5 & -60 & 72.9 & 86.4 & 5.2 & 9.7 & -0.44 & 0.31 & -0.61 & -0.25 \\
\hline & 400 & 49.7 & 48.4 & -60 & 33.7 & 41.8 & 3.1 & 5.8 & -1.48 & 0.13 & -1.05 & -0.25 \\
\hline & 400 & 74.8 & 65.9 & -60 & 51.9 & 63.1 & 3.5 & 5.7 & -1.09 & 0.06 & -1.22 & -0.12 \\
\hline & 401 & 98.2 & 79.1 & -90 & 68.2 & 82.4 & 4.3 & 6.9 & -0.80 & 0.06 & -1.12 & -0.11 \\
\hline & 501 & 40.5 & 38.8 & -80 & 28.9 & 34.7 & 4.0 & 6.9 & -1.06 & 0.16 & -0.88 & -0.20 \\
\hline & 500 & 60.1 & 56.6 & -80 & 41.6 & 50.9 & 3.0 & 5.5 & -1.49 & 0.13 & -1.11 & -0.24 \\
\hline & 501 & 79.7 & 69.0 & -80 & 56.7 & 67.9 & 3.7 & 6.4 & -1.27 & 0.10 & -0.96 & -0.21 \\
\hline & 501 & 101.1 & 80.5 & -90 & 73.5 & 87.8 & 4.4 & 7.3 & -1.17 & 0.10 & -0.76 & -0.16 \\
\hline & 201 & $\overline{9} \overline{9} . \overline{6}$ & $84.9^{-}$ & $-\overline{6} 0$ & $\overline{74} . \overline{6}$ & $\overline{8} 6 . \overline{4}$ & $\overline{8} \overline{\overline{7}}$ & 15.9 & -0.27 & $0 . \overline{4} 7$ & $-0 . \overline{15}$ & -0.49 \\
\hline
\end{tabular}

American Institute of Aeronautics and Astronautics 
Table 1 shows a summary of the results from carrying out total ion current and outer-side divergence angle calculations. The first five columns of the table list basic operating parameters including thruster, discharge voltage, discharge current, anode mass flow rate, and Faraday probe bias voltage, which is measured with respect to the facility ground. The $6^{\text {th }}$ and $7^{\text {th }}$ columns list the total ion current integrated within the 1-e limits and 2-e limits, respectively. The $8^{\text {th }}$ and $9^{\text {th }}$ columns list the outer-side divergence angle calculated within the 1-e limits and 2-e limits, respectively. Calculations with 3-e limits were carried out but are not shown because the resulting total ion current varied from $83 \%$ to $92 \%$ of the discharge current. This was deemed too large to be real. For 1-e and 2-e limits, this percentage is $63-75 \%$ and $78-87 \%$, respectively. For state-of-the-art Hall thrusters, this percentage is typically $70-80 \%,{ }^{12,20,23,24}$ so the correct choice of integration limit appears to lie somewhere between 1-e and 2-e. Since no further information is available to help determine the right integration limits, both 1-e and 2-e values are reported.

One very notable feature of the outer-side divergence angle result is how small they are compared to typical farfield measurement results. Reducing far-field ion current density data typically yield divergence angles in the range of $15-25^{\circ}$ for state-of-the-art Hall thrusters. ${ }^{20,}{ }^{21}$ Yet, the above near-field measurement show that the discharge beam exits the thruster with an average of $4^{\circ}$ and $8^{\circ}$ divergence as calculated with the 1-e and 2-e limits, respectively. We will shortly return to this discrepancy after describing the remainder of the table.

The final four columns of Table 1 shows the coordinates of the points of origin as calculated via procedure described in Section III.C. Unlike the other axial and radial coordinates shown so far, these coordinates are normalized by the discharge channel width of the associated thruster. Their precise definitions of $Z_{c h}$ and $R_{c h}$ are shown in Eq. (3),

$$
\mathrm{Z}_{\mathrm{ch}}=\frac{\mathrm{z}}{\mathrm{W}}, \mathrm{R}_{\mathrm{ch}}=\frac{\mathrm{r}-\mathrm{r}_{\mathrm{cc}}}{\mathrm{W}}
$$

where $\mathrm{W}$ is the discharge channel width and $\mathrm{r}_{\mathrm{cc}}$ is the radial position of the discharge channel centerline associated with the particular side of the thruster. The above special coordinate definitions were used to better show where the points of origin are located with respect to the discharge channel. These special coordinates are not used elsewhere in the paper. For example, $Z_{c h}=0$ and $R_{c h}=0$ is located at the discharge channel exit and the discharge channel centerline. $Z_{\mathrm{ch}}=-1$ would be located deep within the channel. On the $+R$ side of the thruster, $R_{c h}=0.5$ at the outer discharge channel wall, and $R_{c h}=-0.5$ at the inner discharge channel wall. The opposite is true for the $-\mathrm{R}$ side due to the way $R_{c h}$ is defined. A quick look at the values of $R_{c h}$ in Table 1 reveals that without exception all calculated points of origin lie between the discharge channel centerline and the outer channel wall. The average magnitude of $R_{c h}$ is 0.24 , or, in other words, about $1 / 4$ of the channel width away from the outer wall. The average value of $Z_{c h}$ is -0.84 , which is close to the axial position of the anode. In short, the near-field plume of the thrusters look like Gaussian beams that originate from deep inside the channel at about halfway between the channel centerline and the outer wall. With that said, there is a fair amount of variation in the locations of the points of origin.

Note that the last row of Table 1 is labeled "hi-mag". This is results from a side study that was performed and will be discussed in a later section.

\section{Discussions on the Bending and Merging of the Near-Field Plume}

From the results reported thus far, the near-field plume is acting like it is originating not from the center of the channel but from close to one side and has a very small charge-weighted divergence angle on the outer side. One possible explanation for these analysis results is that the near-field plume exits roughly in the axial direction but very quickly turns a slight angle towards the thruster centerline. Furthermore, the analysis suggests that the plume bending occurs within $\sim 0.2$ mean thruster diameter of the exit plane since the rays traced out by the 1-e, 2-e, and 3-e integration limits straightens out after $\mathrm{Z}$ exceeds $\sim 0.2$. If the near-field plume is indeed bending, then the discrepancies in the analysis results are easy to explain. The points of origin appear to be located close to the outer channel wall because they are calculated from ray tracing after the beam had already turned inward. The divergence angle is small because it is calculated by integrating only the outer-side of the plume. If the whole plume is turned inward then the outer-side angle will be pulled inward as well and will appear to be smaller when analyzed. In this case, the inner-side plume will have an increased divergence angle once they cross over each other and move into the far-field.

Another possibility that can explain both the locations of the points of origin and the small divergence angles is that the plasma in the channel is located close to the outer channel wall. In this case, the near-field plume never actually bends but simply shots out of the discharge channel at an angle with respect to axial direction. The first 
counter-argument to this scenario is that the thruster uses a roughly symmetric magnetic field topology. Interior measurements on another thruster of similar topology have already shown that the plasma resides roughly along the channel centerline. ${ }^{25}$ The second counter-argument can be found by fitting Gaussian distributions to the ion current density traces that were taken closest to the channel exit plane, like what is shown in Fig. 9. The location of the center of the Gaussian is left as a fitting parameter. Generally, this location is found to be within several percent of the channel width from the channel center, much smaller in magnitude than how far toward the outer wall the points of origin are. Thus, the most likely explanation is that the discharge channel plume actually exits in the axial direction and then bends toward the thruster centerline within a very short distance.

Evidence of near-field plume bending can also be found in previous near-field Faraday probe studies. For instance, in 2003, Hofer and Gallimore published near-field ion current density results of the NASA-173Mv2 showing the near-field plume from the two sides of the thruster coalescing into one column. ${ }^{10}$ In 2008 , Reid and Gallimore published near-field ion current density results of the H6 showing very similar plume structures. ${ }^{22}$ Neither study was able to definitively offer a mechanism that could explain the plume merging. Interestingly, the NASA$173 \mathrm{Mv} 2$ used a side-mounted cathode while the H6 used a centrally-mounted cathode. Both the NASA-173Mv2 and the H6 uses magnetic lens topology similar to the NASA-300M and NASA-457Mv2.

Thus far, the present study has also not been able to definitively identify a cause for near-field plume bending. One possible explanation is the presence of the cathode in the center of the thruster, which is negatively biased with respect to the near-field plume. There are two counter-arguments against the centrallymounted cathode being the main reason for plume bending. One, as mentioned above, there are signs of bending even when the cathode is side-mounted. Two, the region affected by the negative bias of the cathode does not appear to extend very far in the radial direction. Figure 24 shows a flooded contour plot of the plasma potential for the $457 \mathrm{Mv} 2$ operating at $300 \mathrm{~V}, 100 \mathrm{~A}$. Plasma potential data was taken using the emissive probe on the probe array, which is described in a companion paper. ${ }^{19}$ In this figure, negative potential created by the centrally-mounted cathode appears as deep blue along the thruster centerline. The radial extend of this deep blue region is about \pm 0.05 in normalized radial

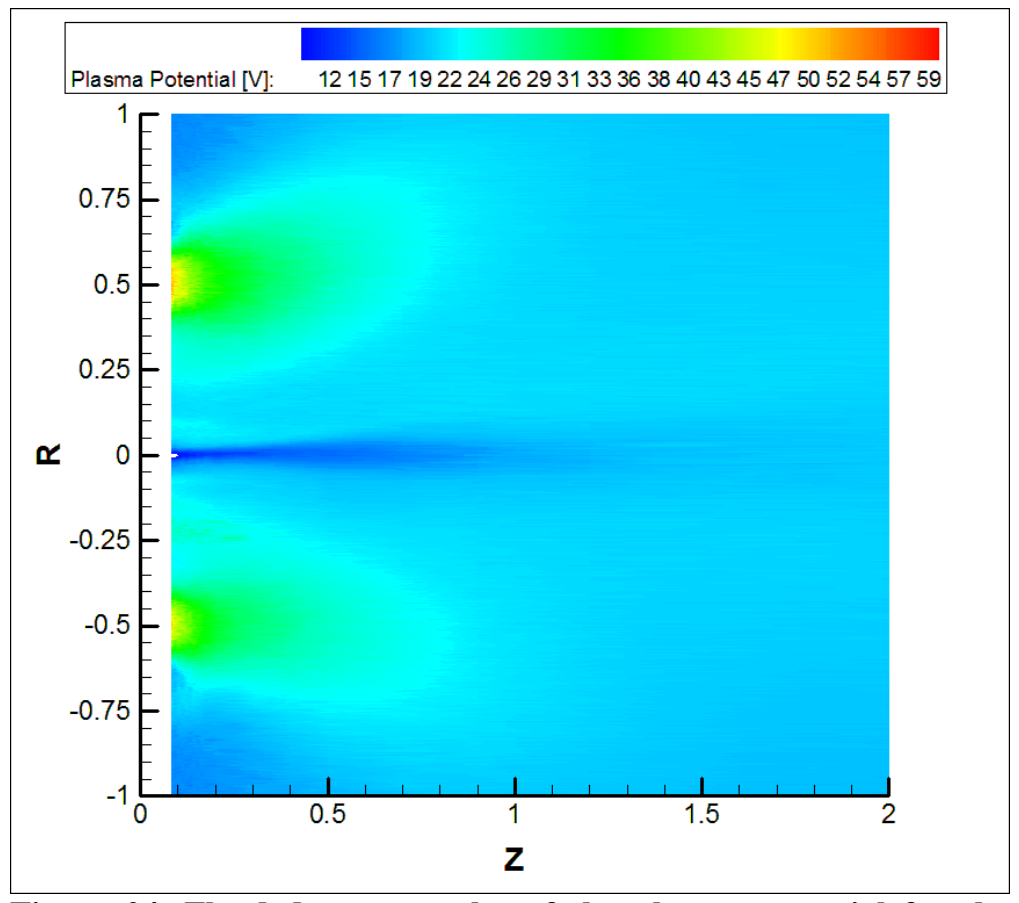

Figure 24. Flooded contour plot of the plasma potential for the $457 \mathrm{Mv} 2$ operating at $300 \mathrm{~V}, 100 \mathrm{~A}$.

coordinate. In contrast, the plasma potential gradient spilling out from the discharge channel is several times wider in the radial direction. If this trend can be generalized to other Hall thrusters, the limited radial influence of the cathode could explain why the cathode position does not appear to be a driving factor in near-field plume bending. On the other hand, since the near-field Faraday probe studies cannot extend all the way to $Z=0$ due to physical limitations, it is conceivable that there are additional structures there which can explain near-field plume bending.

While the locations of the points of origin can be explained by near-field plume bending, the discrepancy between near-field divergence angle and far-field divergence angle requires a closer look at what happens to the plume in the transitional region. There are a number of different phenomena that can be occurring in the transitional region and, broadly speaking, they fall under two scenarios; the transitional plume is either self-interacting, or nonself-interacting. Studying the possible self-interaction mechanism in the transitional region is left for future works. Instead, we will discuss some of the possible implications if the plume is self-interacting versus non-self-interacting.

If the plume is non-self-interacting, or only slightly self-interacting, the transitional region plume structure can be reproduced by simply overlapping the Gaussian beams from the two sides of the thruster with the cathode plume. The three plume structures will linearly superimpose on top of each other. In this case, the fact that the far-field divergence angle is so much larger than the near-field divergence angle can be attributed purely to the bending of the 
near-field plume at $Z<0.2$. This bending effect acts much like a lens that over-focuses the overall plume such that the plume from the $+\mathrm{R}$ and $-\mathrm{R}$ sides of the thruster shoot past each other and outward into the far-field. If this is the correct physical picture, discovering the root cause of the near-field plume bending and "un-bending" the plume could potentially decrease the far-field plume divergence and increase the overall performance of the thruster.

If the plume is self-interacting to a degree that the self-interaction is what determines the far-field divergence angle, and if that self-interaction transmits forces back to the thruster, then the near-field plume bending may have no influence on the overall divergence angle. However, controlling the near-field bending could still have an effect on the location where the plume self-interaction occurs. For instance, if plume self-interaction produces ions that shoot backward and side-ways to interact with the rest of the spacecraft, pushing the interaction zone outward could reduce the flux of backward moving particles.

With all this said, plume bending may be a fundamental aspect of the near-field plasma structure and cannot be removed. Further investigation is needed to discover the root cause of near-field plume bending and what, if any, applications there are to controlling the bending.

As a final note for this section, all of the operating conditions that have the "triceratops" plume structure also have points of origin that are fairly close to the channel exit plane (as opposed to close to the anode) and the outer channel wall. In other words, the near-field plumes for these operating conditions appear to bend a distinctly greater amount than for other operating conditions. This is another piece of evidence that operating conditions with "triceratops" plumes may be operating in a different mode than ones with "trident" plumes.

\section{High-Magnetic-Field-Strength Study}

As previously mentioned, the NASA-457Mv2 is a successor to the NASA-457M. A 2002 paper published by Manzella describes the operation of the NASA-457M, which used a higher magnetic field than the NASA-457Mv2. ${ }^{6}$ In order to make comparisons between operation of the NASA-457M and the NASA-457Mv2, a series of "hi-mag" operating conditions were chosen for the 457Mv2 testing. Of these operating conditions, near-field Faraday probe data was taken for one of them. The 200-V, 100-A, "hi-mag" condition for the 457Mv2 uses a magnetic field of roughly the same shape as the normal $200-\mathrm{V}, 100-\mathrm{A}$ operating condition but the field magnitude is about twice as high. A quick look at Table 1 reveals that for 200-V, 100-A operation, operating in "hi-mag" mode results in a 4 A, or $5 \%$, increase in total ion current. The anode mass flow rate was increased by $~ 9 \%$ to keep the discharge current constant. Interestingly, both modes of operation results in "triceratops" type near-field plume structure, though the "hi-mag" mode plume structure shows distinctly less merging between the cathode plume and the rest of the plume structure. This behavior may be a result of stronger magnetic field keeping the channel plasma away from the thruster centerline.

\section{Conclusion and Future Work}

Near-field ion current density data has been successfully collected for the NASA-300M and NASA-457Mv2 Hall thrusters as a part of an effort to aid the validation of a JPL Hall thruster model. The refined model will be used to help the design and development of a flight-like 30 to 50-kW Hall thruster in support of NASA's future mission needs.

In the process of analyzing the aforementioned data, a novel ray-tracing approach based on laser beam physics was used to determine the points of origin for divergence analysis. The results across all 21 operating conditions of both Hall thrusters showed that the near-field plume acts like a Gaussian beam until it starts to merge with the cathode plume. Furthermore, the Gaussian beams behave as if they originate, on the average, from a position that is radially $1 / 4$ of the channel width away from the outer channel wall and at about the same axial position as the anode. It is hypothesized that the near-field plume is actually roughly centered in the discharge channel but undergoes a slight turning towards the thruster centerline between the channel exit plane and 0.2 mean thruster diameters downstream of the channel exit plane. The root cause of this slight bending is unclear but it does explain why the calculated outer-side divergence angle is, on the average, only $4-8^{\circ}$ when far-field plume divergence is typically 15 $25^{\circ}$.

Inspection of the flooded contours of ion current density reveal two different types of near-field plume structures that may be inter-related. The two plume structure types are tentatively nicknamed "trident" and "triceratops". Interestingly, "triceratops" type plume structure is correlated with a large degree of plume bending. Root cause for the differences between the two plume structure types is currently unclear.

Lastly, a short study of the plume while roughly doubling the magnetic field strength reveal that the overall plume shape does not change greatly but the cathode plume becomes more distinctly separated from the overall 
plume structure. While the anode mass flow rate was increased by $~ 9 \%$ to keep the discharge current constant, the total ion current increased by $\sim 5 \%$ when operating with the higher magnetic field strength.

Several tasks have been planned for future works. First, far-field Faraday probe measurements will be recorded while matching the operating conditions to obtain far-field divergence angle for comparison with the near-field measurements. Second, we will find a way to analyze the inner-side of the near-field plume for charge-weighted divergence angle. Third, we will find a way to calculate the effective angle by which the near-field plume has bent. Fourth, an attempt will be made to model the near-field plume by first assuming a non-self-interacting plume. The goal is to see whether modeling the near-field plume as simple Gaussian beams can replicate the plume structures seen in the flooded contours of ion current density. Fifth, we will determine the root cause of the plume bending and, if possible, find a way to control the bending. 


\section{Appendix}

Figures 25 to 29 shows flooded contours of ion current density in the near-field and transitional region of the NASA-300M.

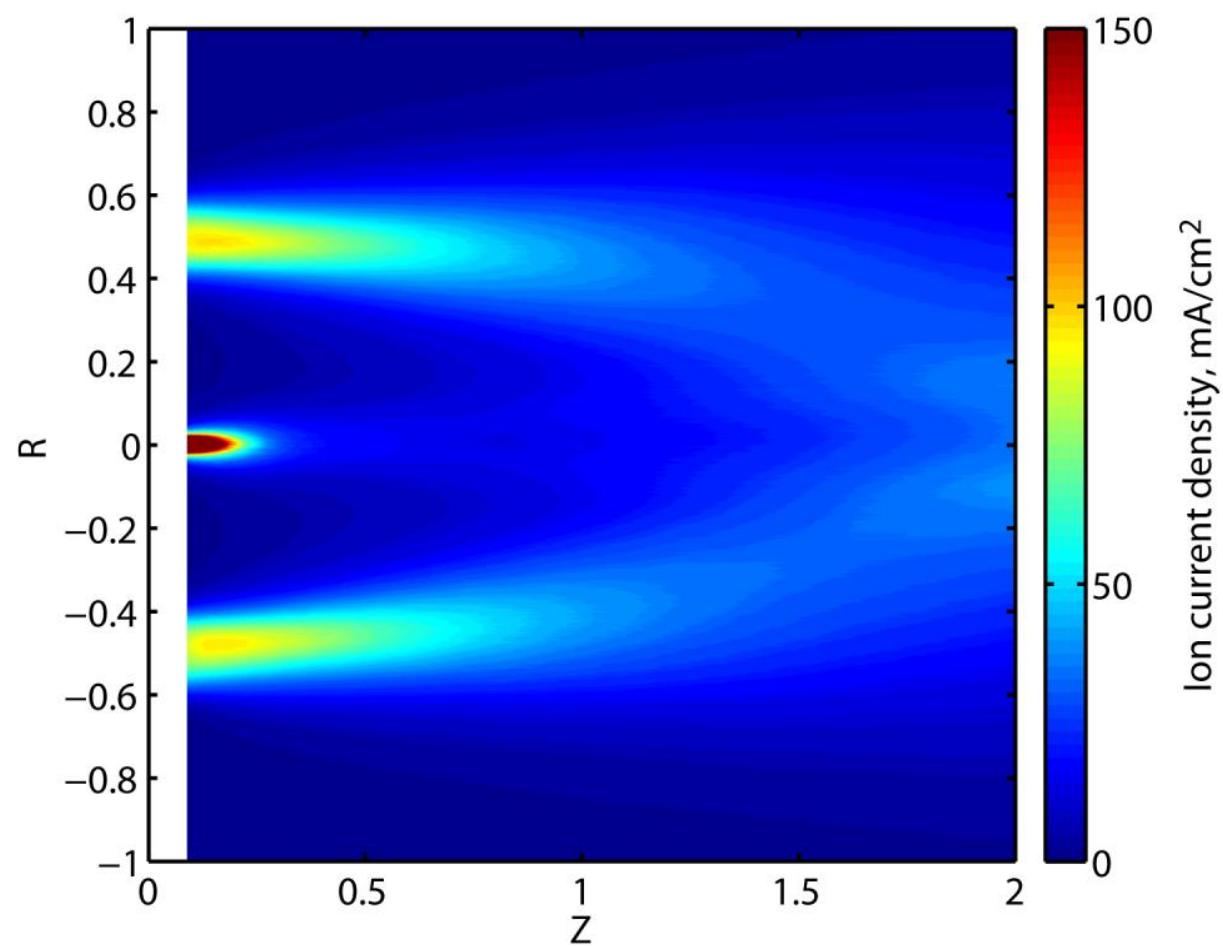

Figure 25. Flooded contour of ion current density for the $300 \mathrm{M}$ operating at $300 \mathrm{~V}, 33 \mathrm{~A}$.

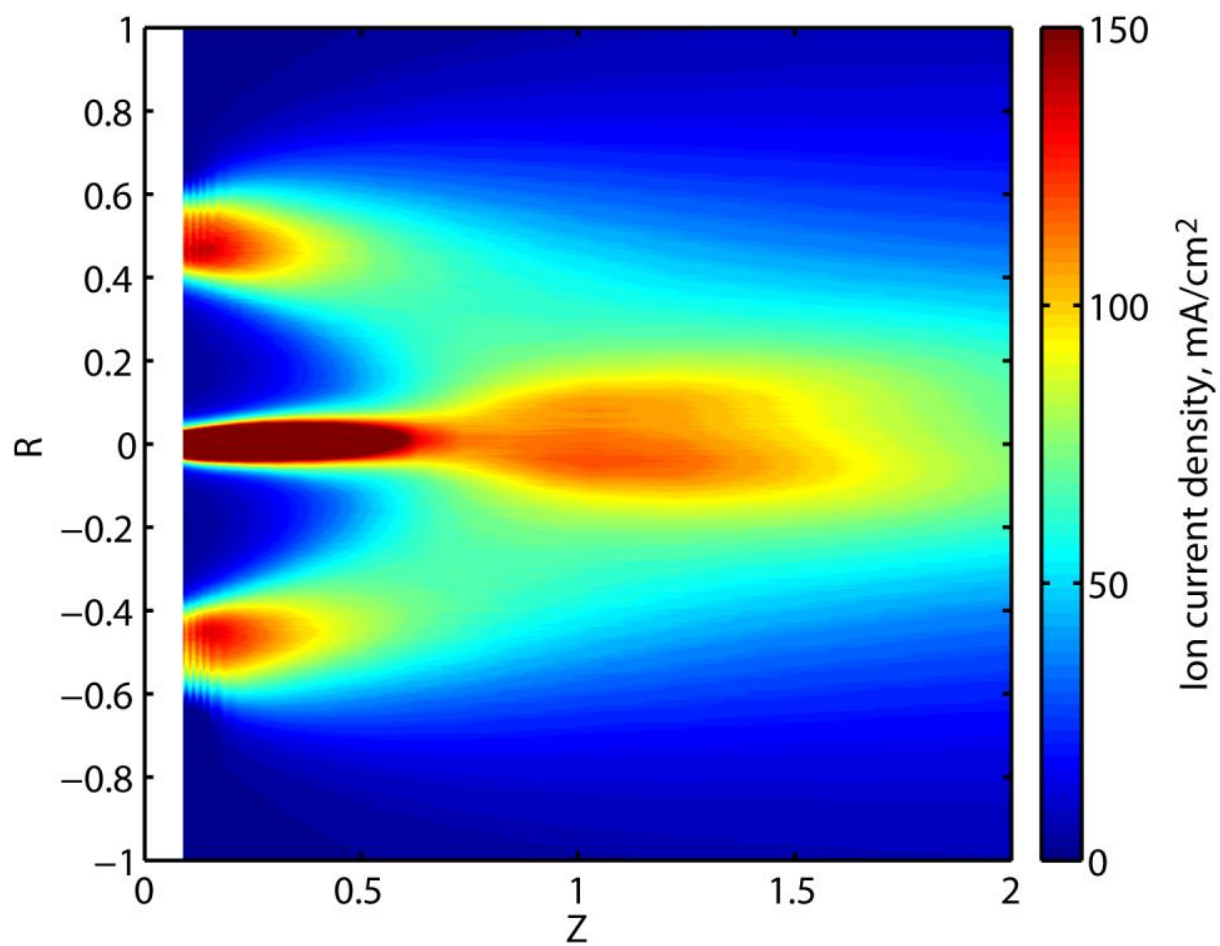

Figure 26. Flooded contour of ion current density for the 300M operating at $300 \mathrm{~V}, 67 \mathrm{~A}$. 


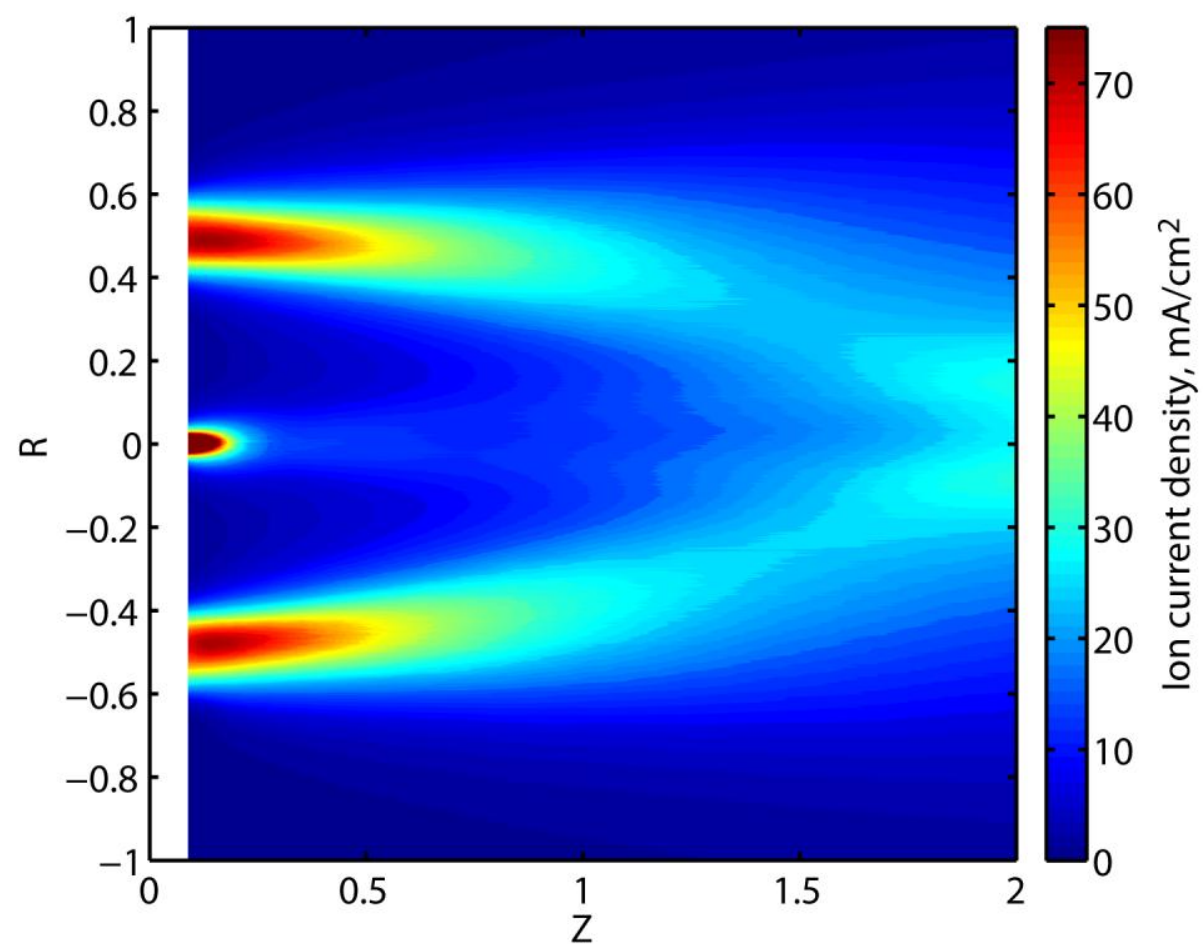

Figure 27. Flooded contour of ion current density for the 300M operating at $400 \mathrm{~V}, 25 \mathrm{~A}$.

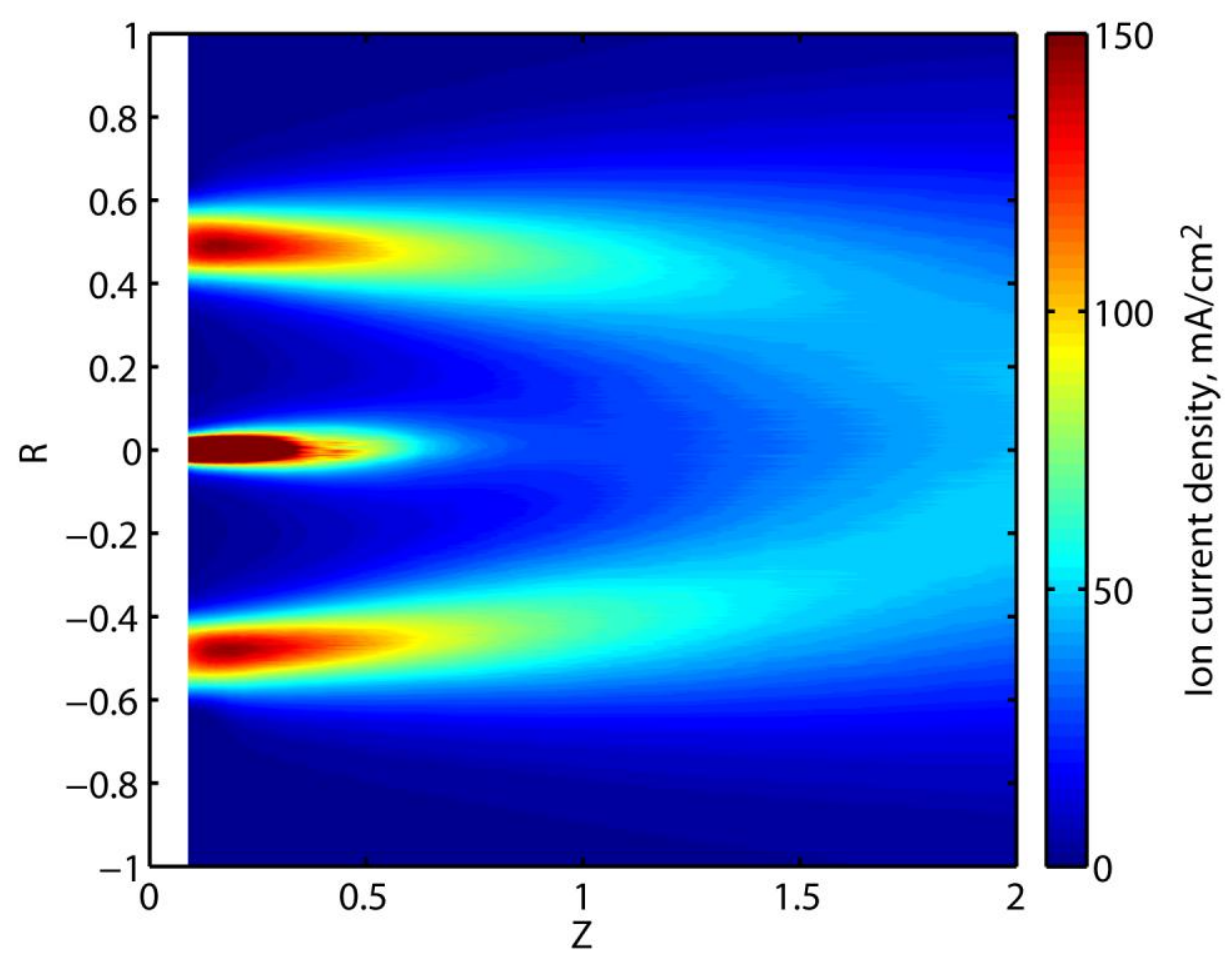

Figure 28. Flooded contour of ion current density for the $300 \mathrm{M}$ operating at $400 \mathrm{~V}, 50 \mathrm{~A}$. 


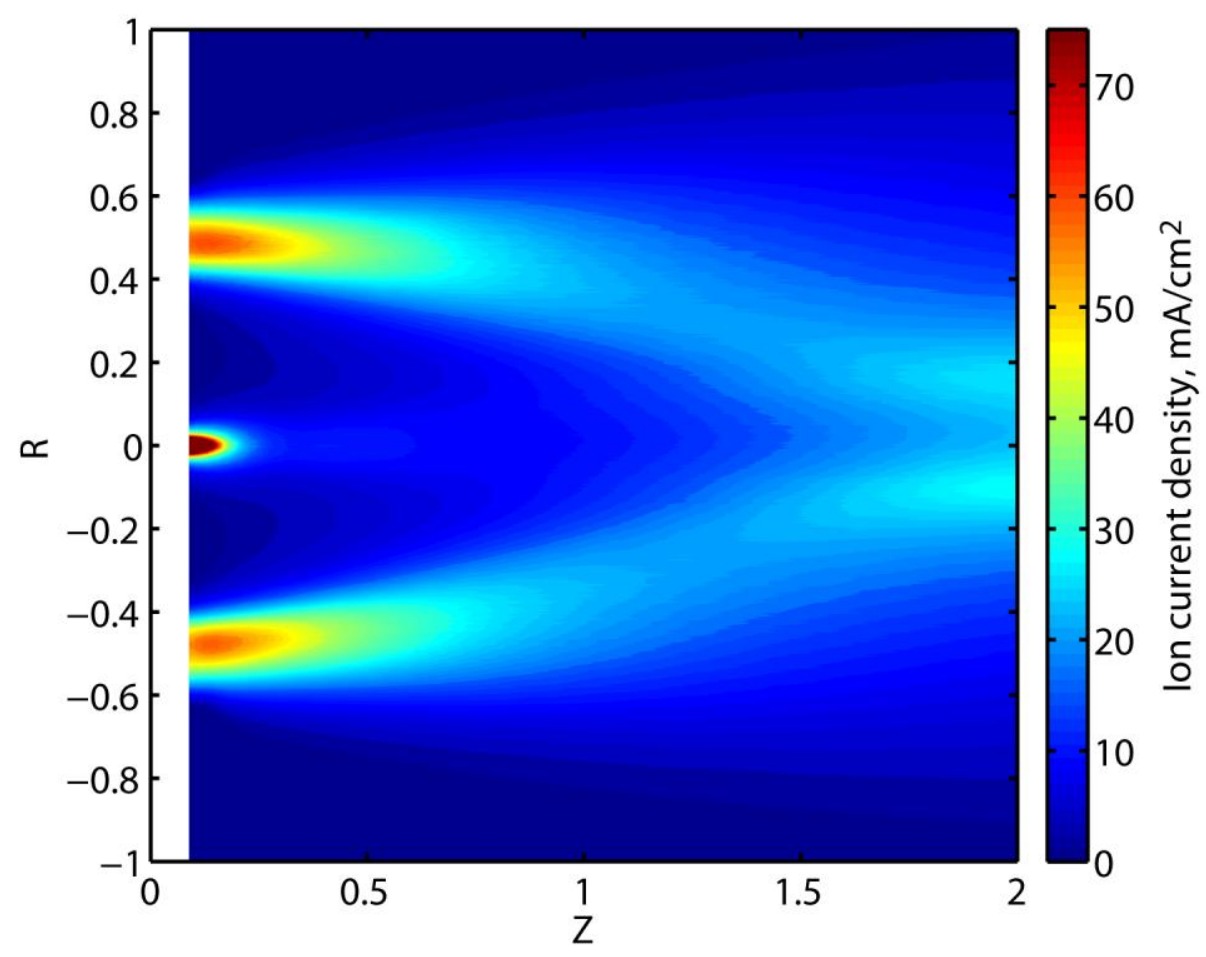

Figure 29. Flooded contour of ion current density for the 300M operating at $500 \mathrm{~V}, 20 \mathrm{~A}$. 
Figures 30 to 43 shows flooded contours of ion current density in the near-field and transitional region of the NASA-457Mv2.

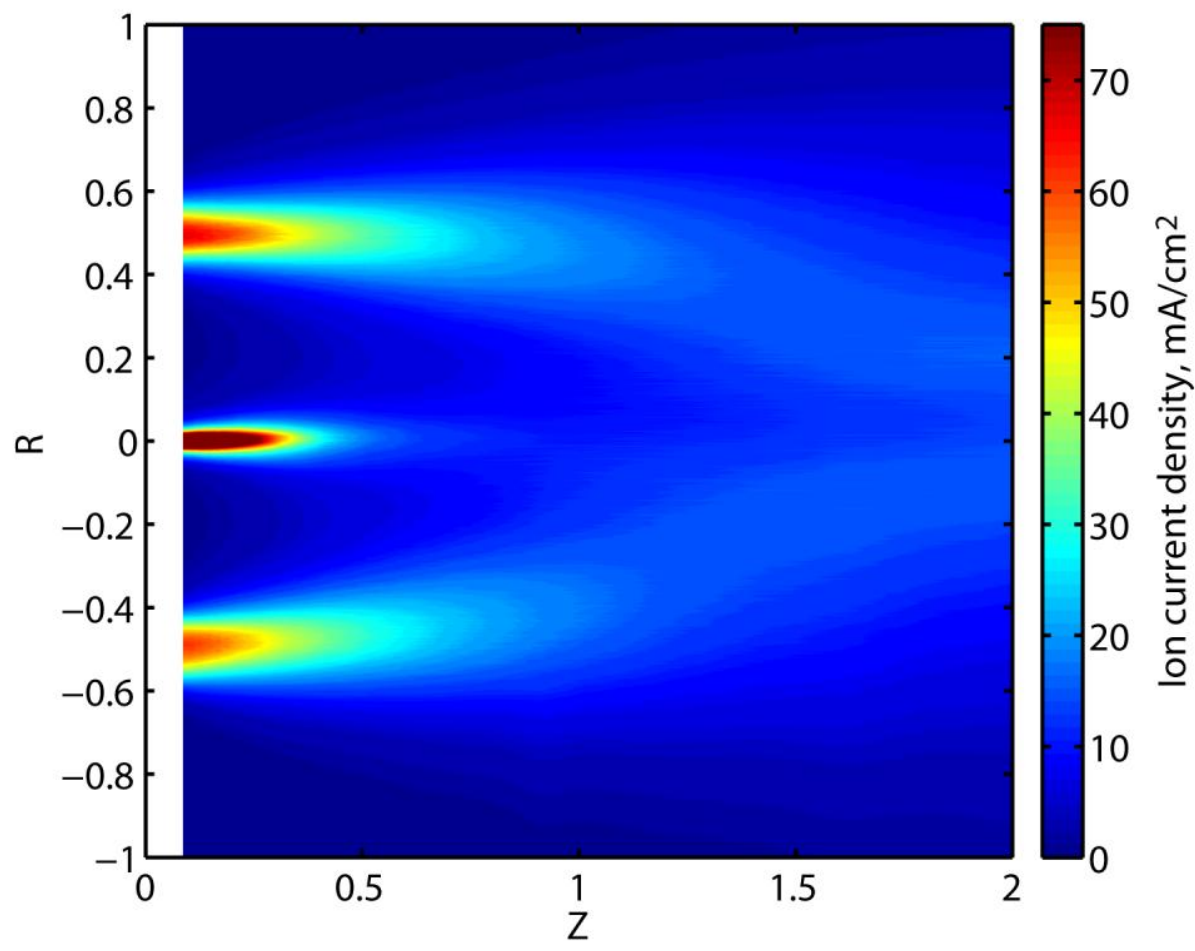

Figure 30. Flooded contour of ion current density for the 457Mv2 operating at $200 \mathrm{~V}, 49 \mathrm{~A}$.

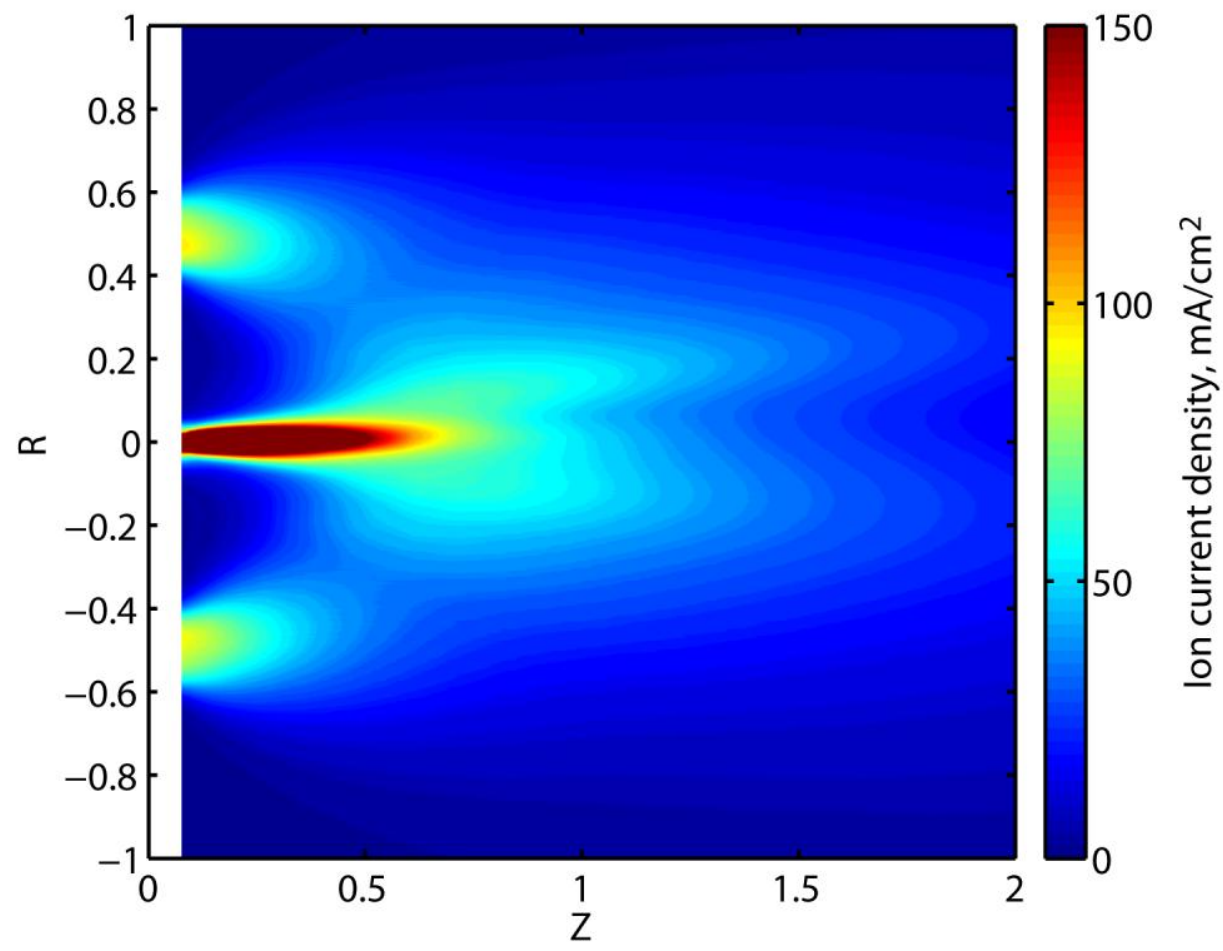

Figure 31. Flooded contour of ion current density for the 457Mv2 operating at $200 \mathrm{~V}, 100 \mathrm{~A}$. 


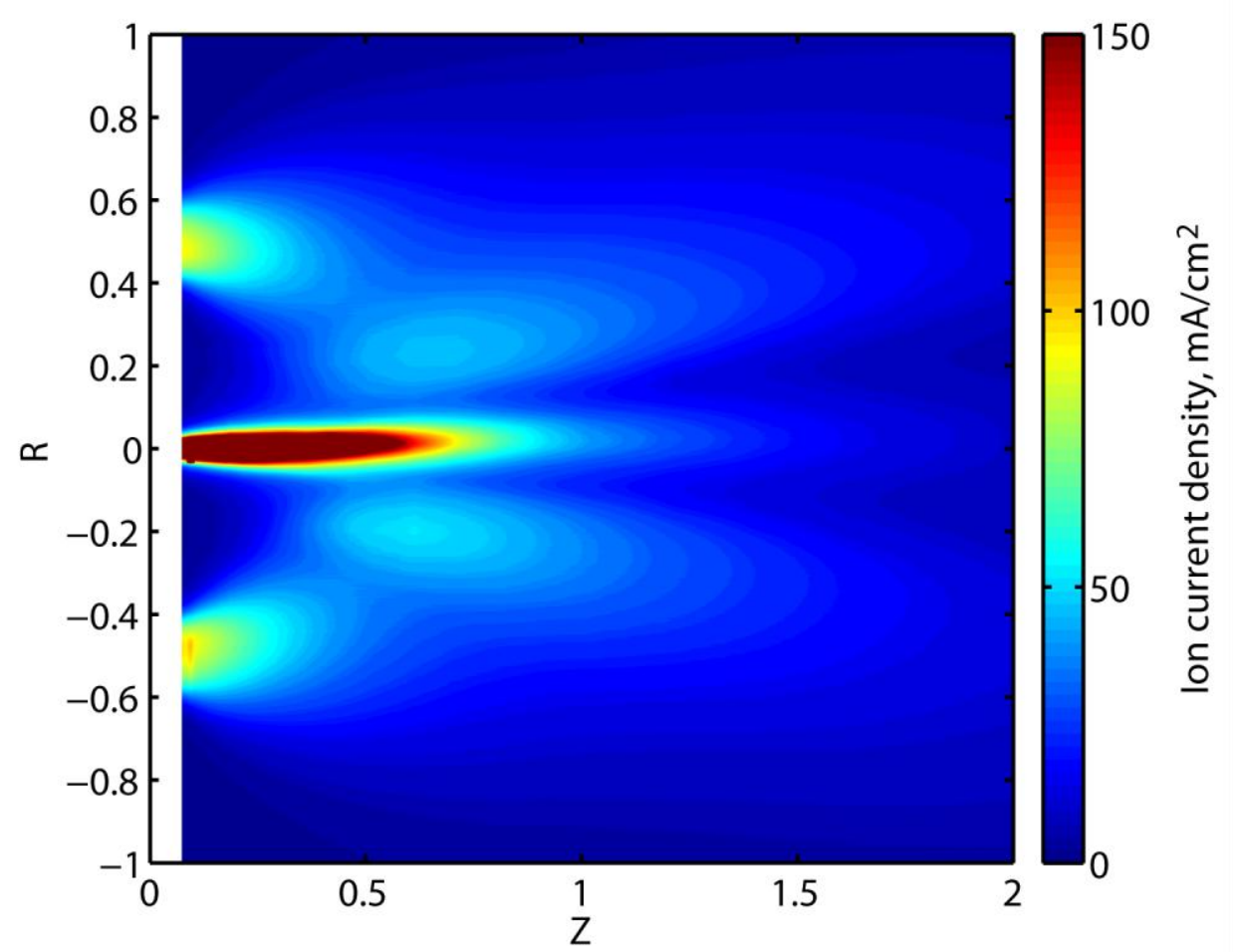

Figure 32. Flooded contour of ion current density for the 457Mv2 operating at $200 \mathrm{~V}, 100 \mathrm{~A}$, "hi-mag".

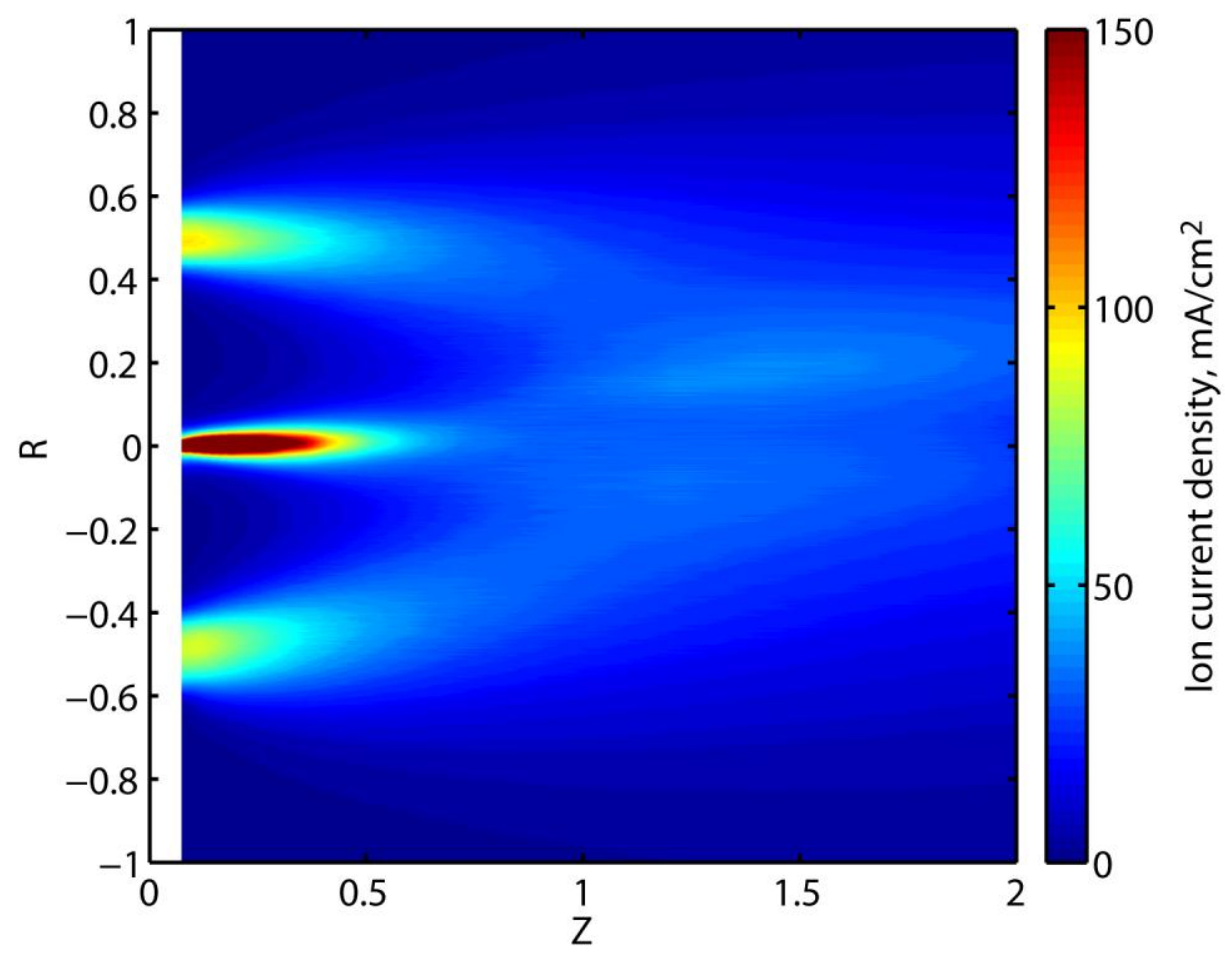

Figure 33. Flooded contour of ion current density for the 457Mv2 operating at $250 \mathrm{~V}, 80 \mathrm{~A}$. 


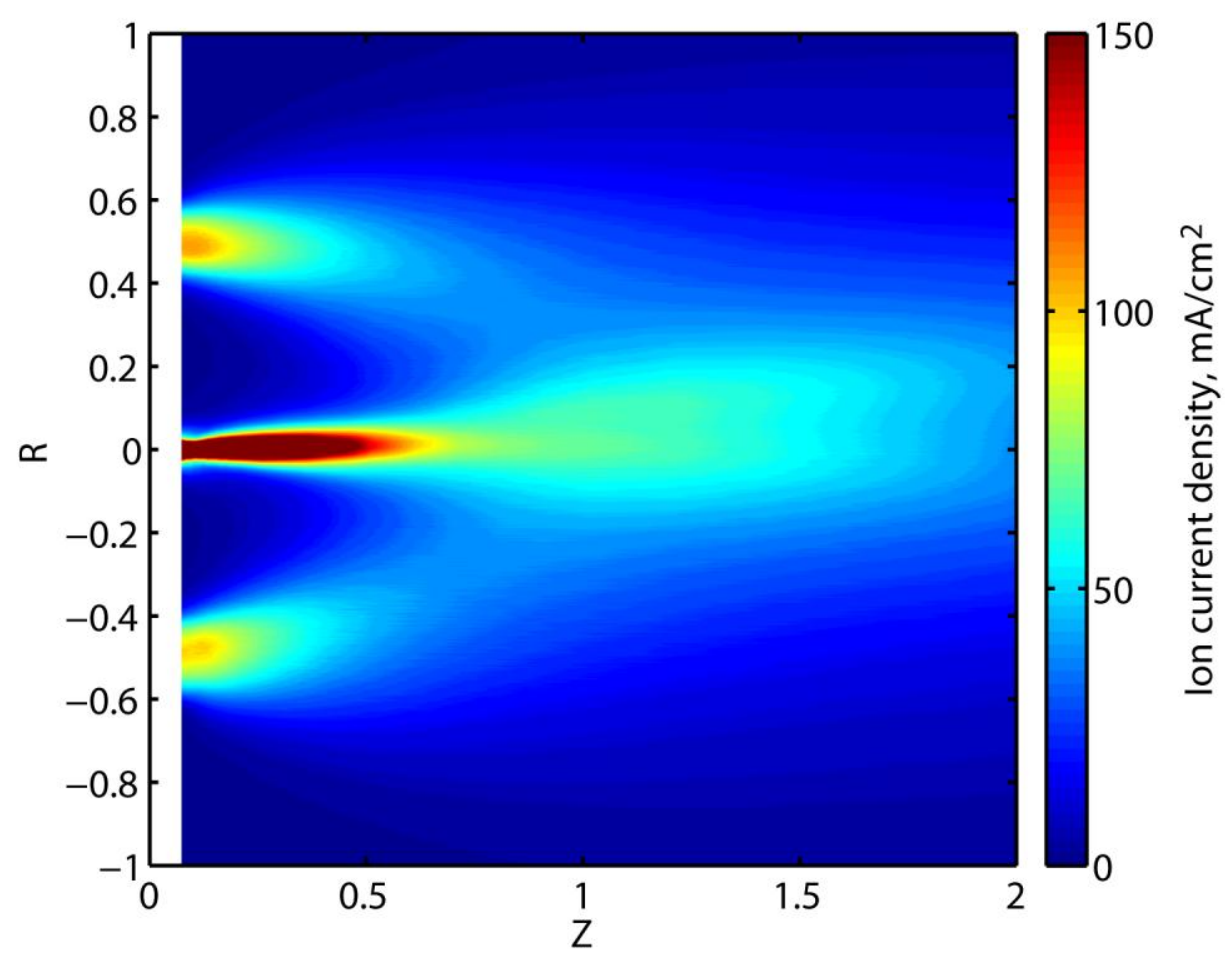

Figure 34. Flooded contour of ion current density for the 457Mv2 operating at $250 \mathrm{~V}, 100 \mathrm{~A}$.

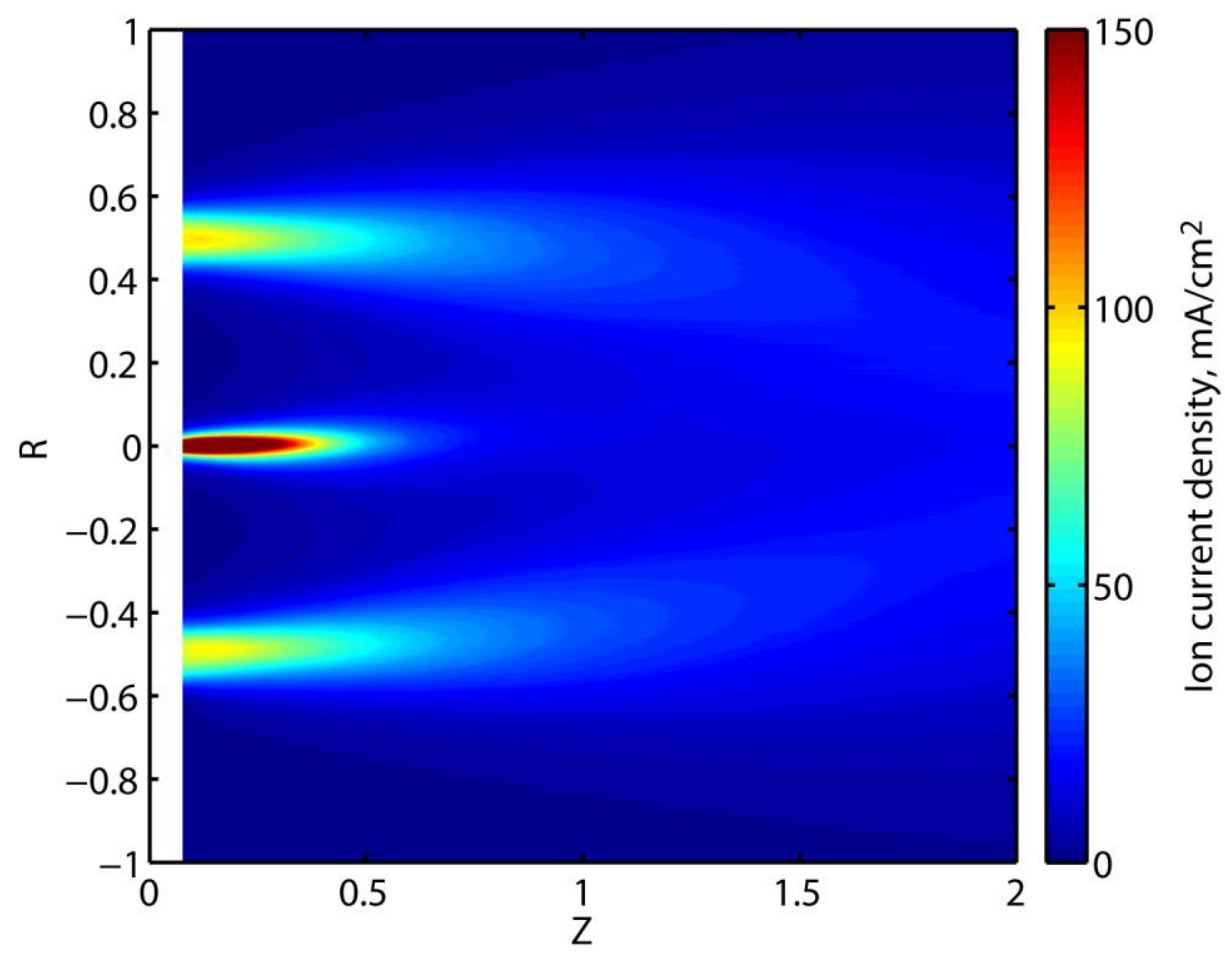

Figure 35. Flooded contour of ion current density for the 457Mv2 operating at $300 \mathrm{~V}, 66 \mathrm{~A}$. 


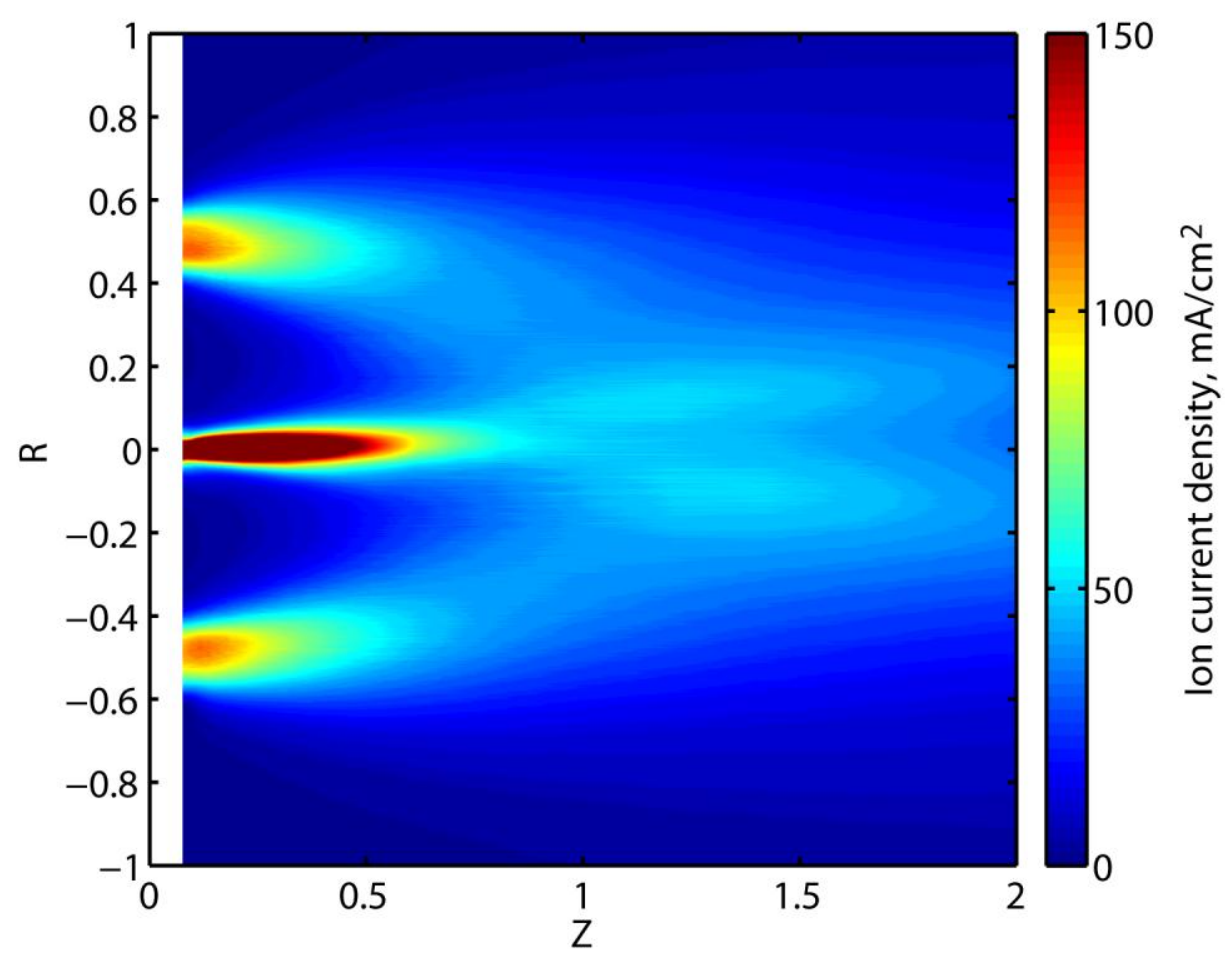

Figure 36. Flooded contour of ion current density for the 457Mv2 operating at $300 \mathrm{~V}, 100 \mathrm{~A}$.

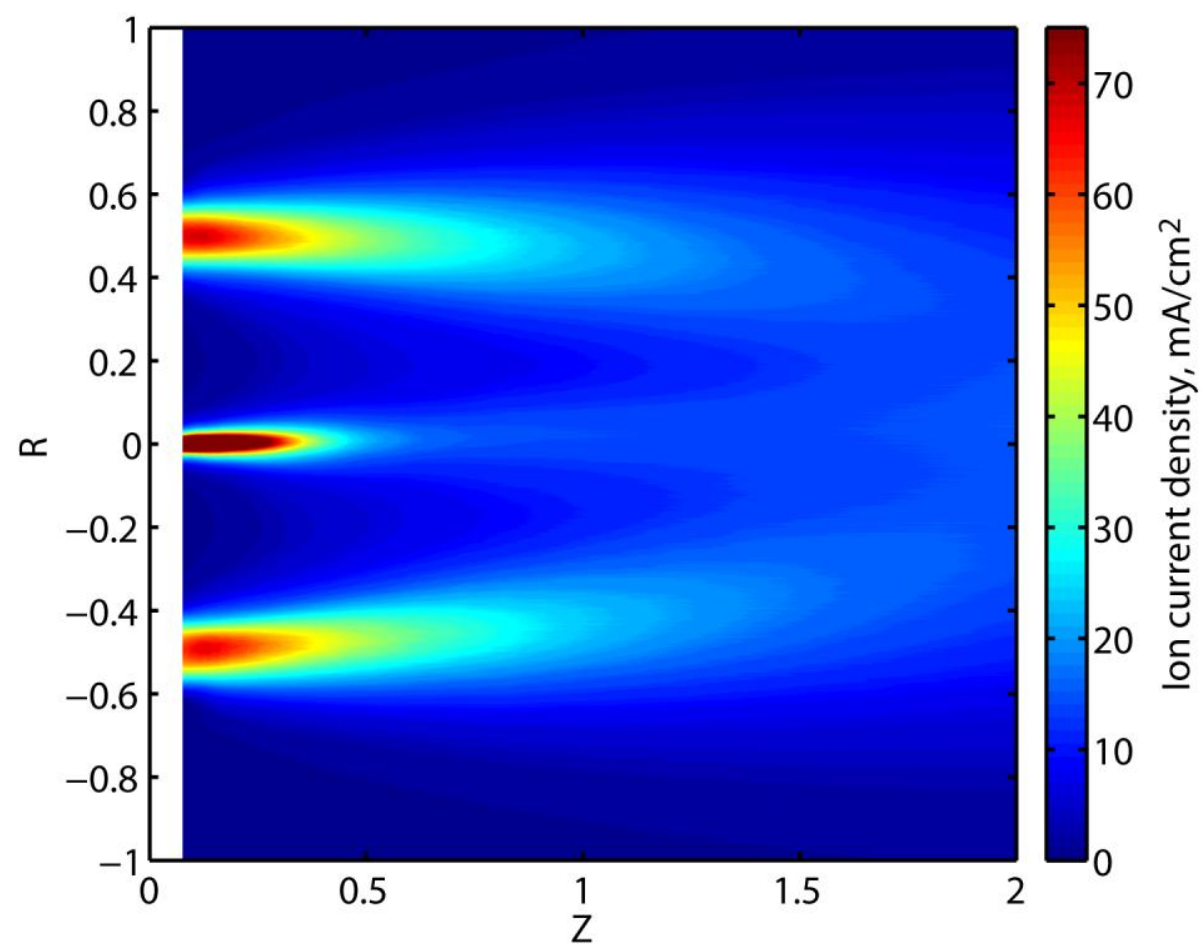

Figure 37. Flooded contour of ion current density for the 457Mv2 operating at $400 \mathrm{~V}, 50 \mathrm{~A}$. 


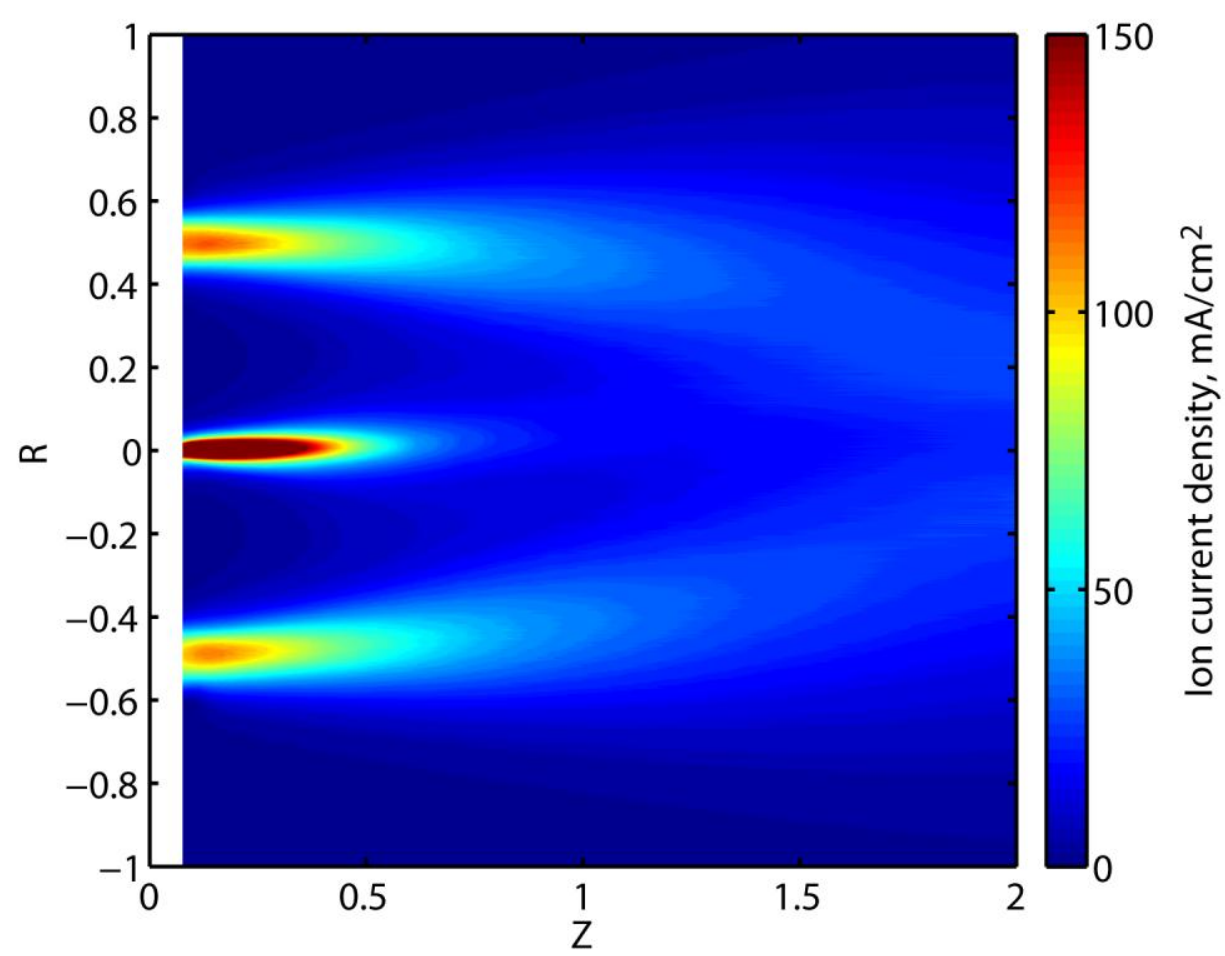

Figure 38. Flooded contour of ion current density for the $457 \mathrm{Mv} 2$ operating at $400 \mathrm{~V}, 75 \mathrm{~A}$.

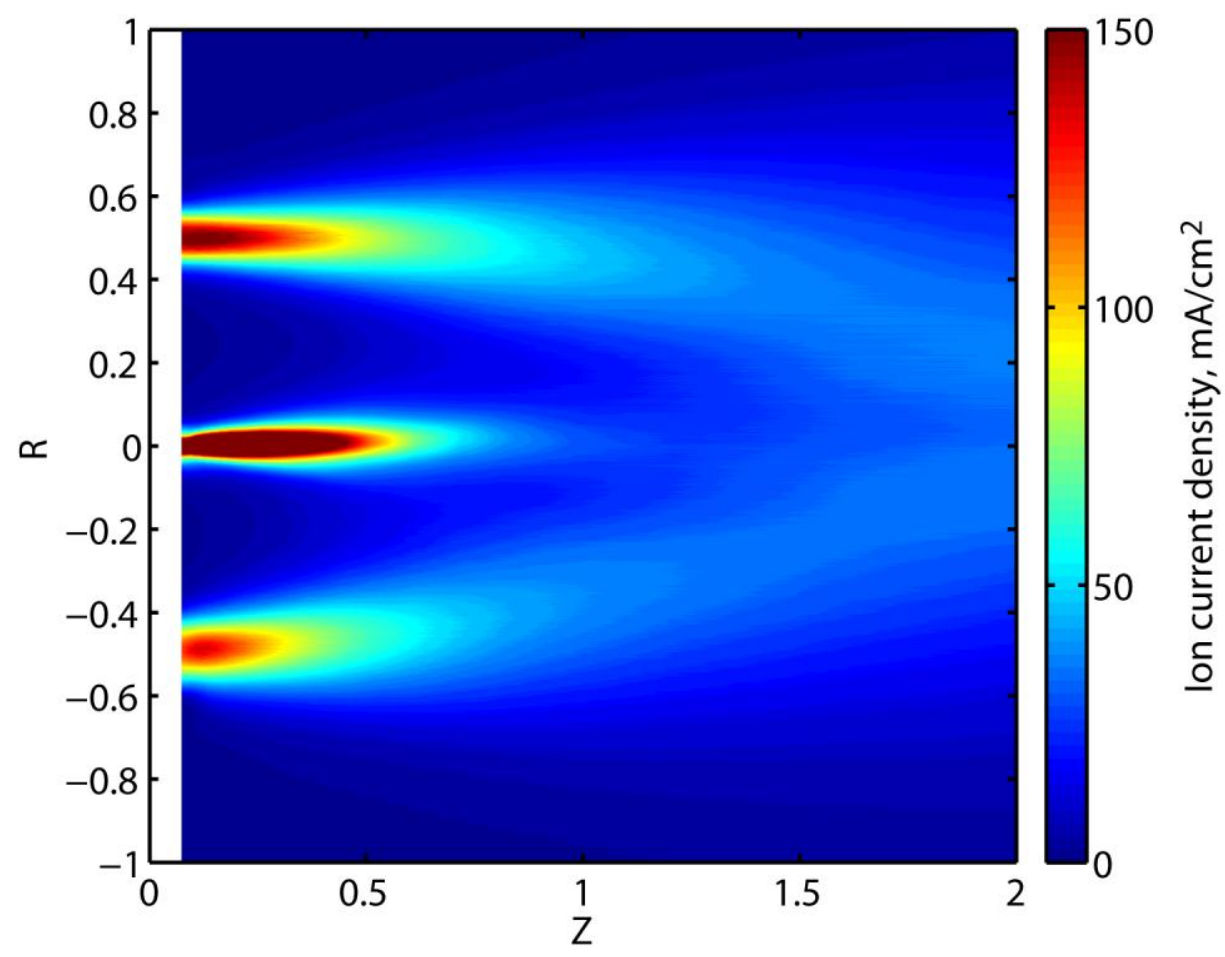

Figure 39. Flooded contour of ion current density for the 457Mv2 operating at $400 \mathrm{~V}, 98 \mathrm{~A}$. 


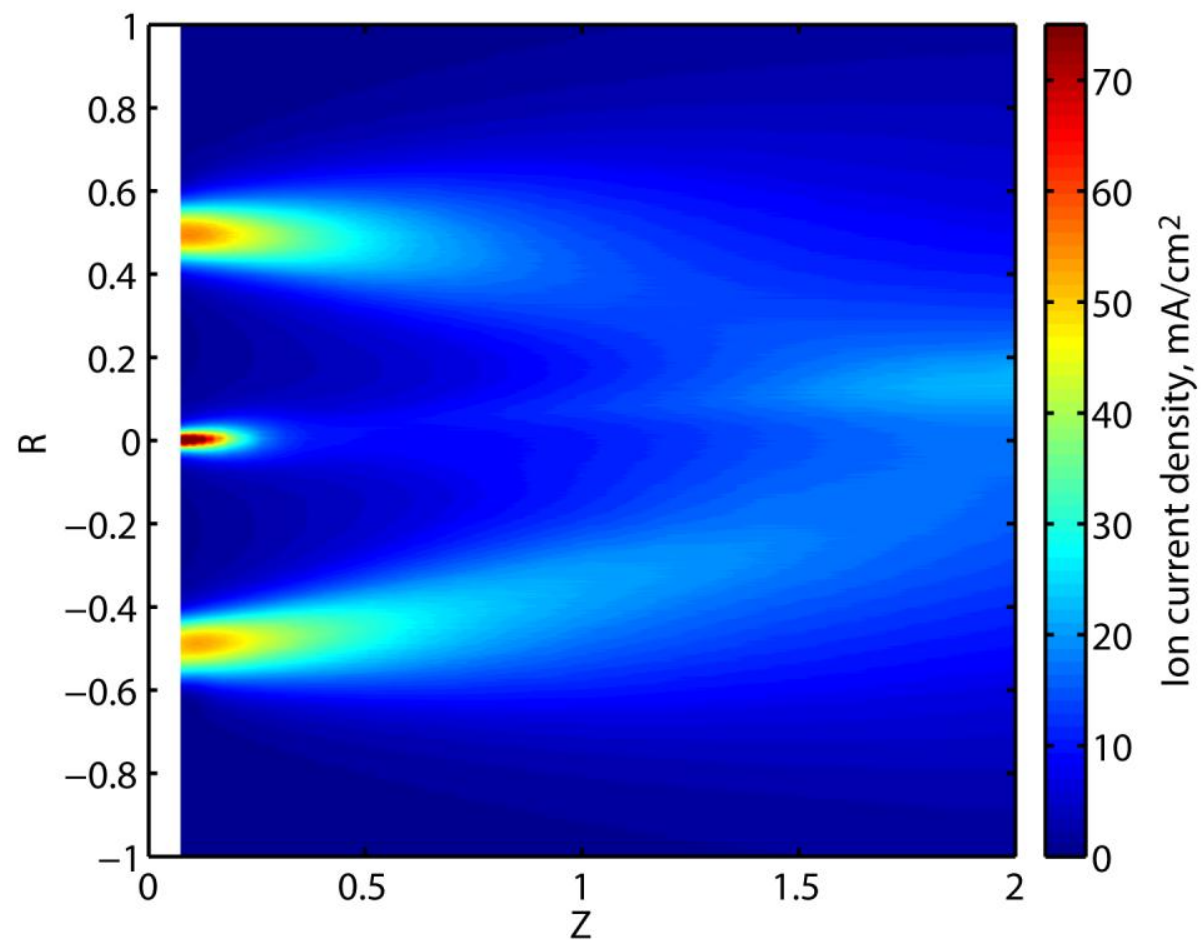

Figure 40. Flooded contour of ion current density for the $457 \mathrm{Mv} 2$ operating at $500 \mathrm{~V}, 40 \mathrm{~A}$.

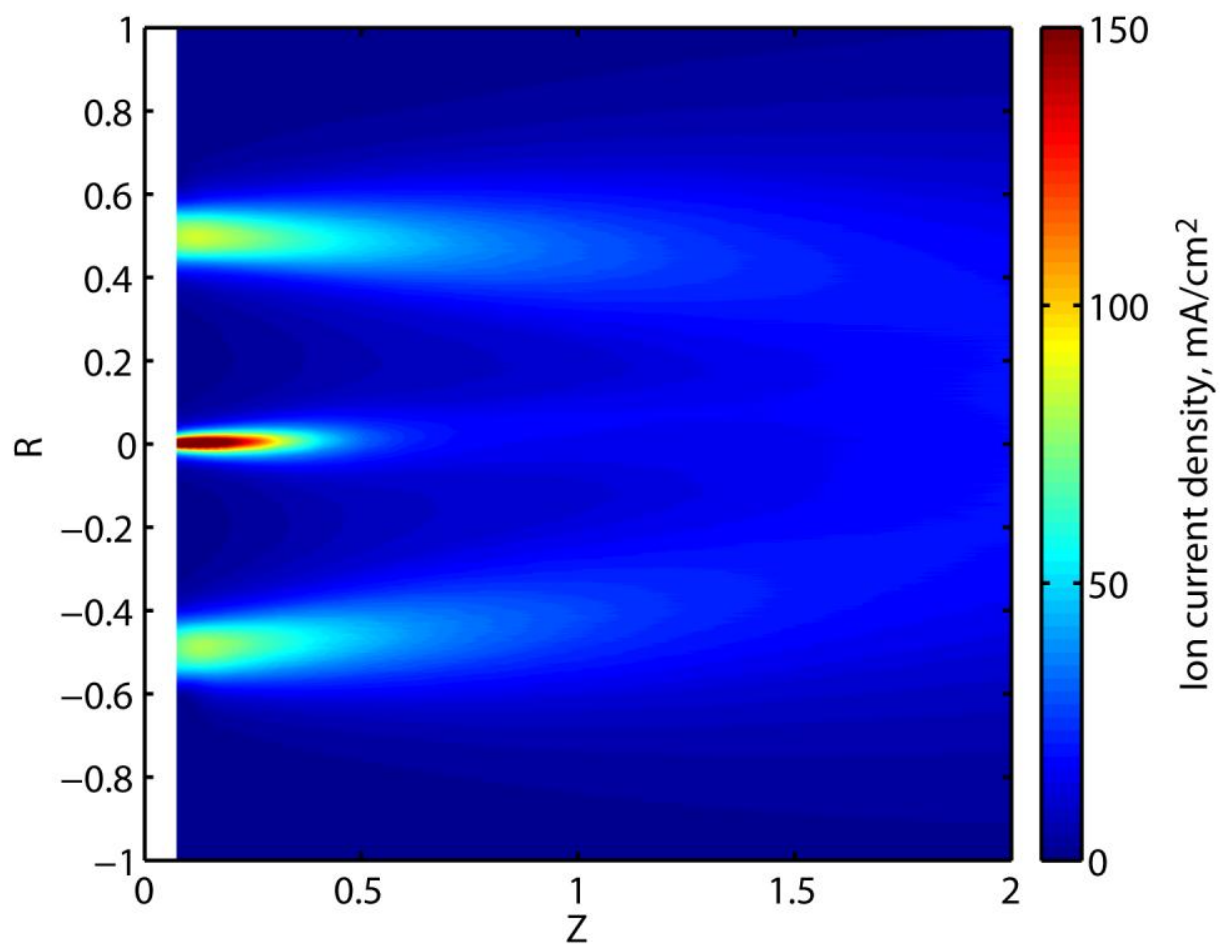

Figure 41. Flooded contour of ion current density for the 457Mv2 operating at $500 \mathrm{~V}, 60 \mathrm{~A}$. 


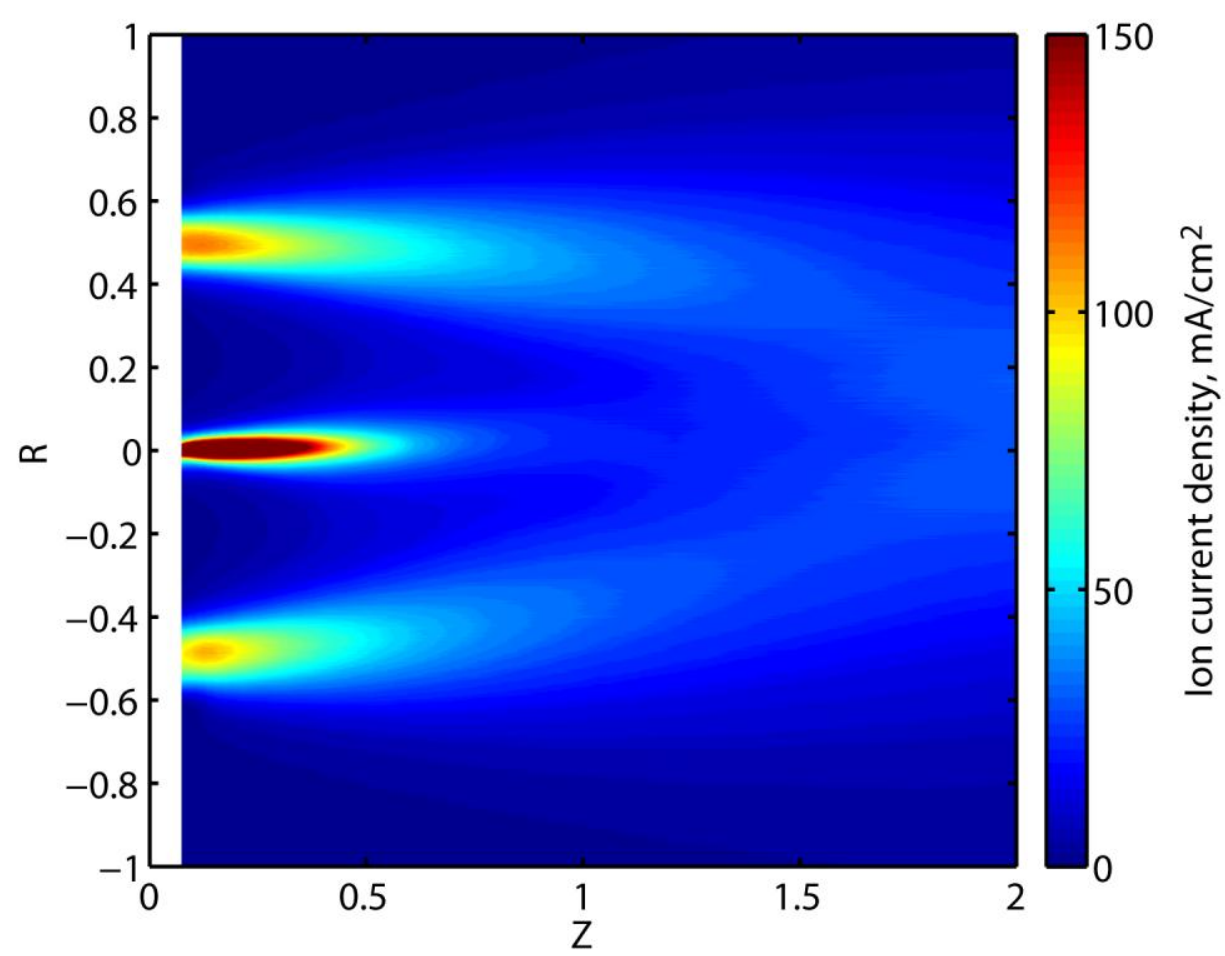

Figure 42. Flooded contour of ion current density for the 457Mv2 operating at $500 \mathrm{~V}, 80 \mathrm{~A}$.

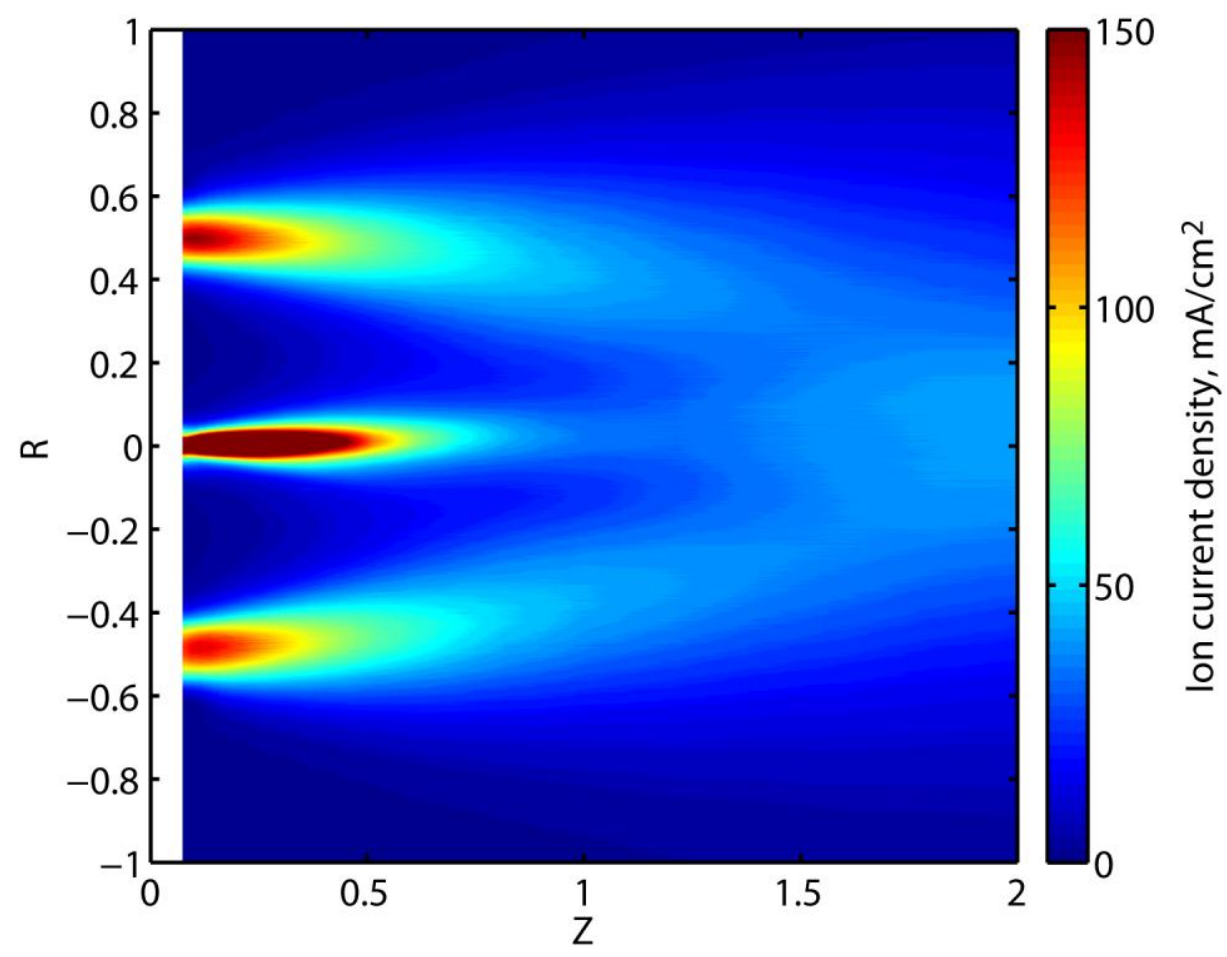

Figure 43. Flooded contour of ion current density for the 457Mv2 operating at $500 \mathrm{~V}, 101 \mathrm{~A}$. 


\section{Acknowledgments}

We thank the NASA Office of Chief Technologist In-Space Propulsion project for funding this work, and Timothy D. Smith for managing the OCT ISP project. We acknowledge David M. Manzella, David T. Jacobson, and Robert S. Jankovsky for the design and fabrication of the NASA-457Mv2 Hall thruster, and Peter Peterson and Christopher Griffith for the design of the NASA-300M Hall thruster. We also acknowledge Kevin L. Blake, George W. Readus, and George P. Jacynycz for the thruster fabrication, assembly of the test setup, and operation of the vacuum facility.

\section{References}

1"NASA Exploration Systems Mission Directorate Presentation, Human Space Exploration Summary", http://www.nasa.gov/exploration/new_space_enterprise/home/heft_summary.html, Jan., 2011.

${ }^{2}$ Mercer, C. R., et al., "Benefits of Power and Propulsion Technology for a Piloted Electric Vehicle to an Asteroid ", 47th AIAA/ASME/SAE/ASEE Joint Propulsion Conference \& Exhibit, AIAA-2011-7252, San Diego, CA, 31 Jul.- 3 Aug., 2011.

${ }^{3}$ Capadona, L. A., et al., "Feasibility of Large High-Powered Solar Electric Propulsion Vehicles: Issues and Solutions", 47th AIAA/ASME/SAE/ASEE Joint Propulsion Conference \& Exhibit, AIAA-2011-7251, San Diego, CA, 31 Jul.- 3 Aug., 2011.

${ }^{4}$ Brophy, J. R., et al., "300-kW Solar Electric Propulsion System Configuration for Human Exploration of Near-Earth Asteroids", 47th AIAA/ASME/SAE/ASEE Joint Propulsion Conference \& Exhibit, AIAA-2011-5514, San Diego, CA, 31 Jul.- 3 Aug., 2011.

${ }^{5}$ Hofer, R. R. and Randolph, T. M., "Mass and Cost Model for Selecting Thruster Size in Electric Propulsion Systems", 47th AIAA/ASME/SAE/ASEE Joint Propulsion Conference \& Exhibit, AIAA-2011-5518, San Diego, CA, 31 Jul.- 3 Aug., 2011.

${ }^{6}$ Manzella, D. H., Jankovsky, R. S., and Hofer, R. R., "Laboratory Model 50 kW Hall Thruster", 38th AIAA/ASME/SAE/ASEE Joint Propulsion Conference \& Exhibit, AIAA-2002-3676, Indianapolis, IN, 7-10 Jul., 2002.

${ }^{7}$ Kamhawi, H., Haag, T. W., Jacobson, D. T., and Manzella, D. H., "Performance Evaluation of the NASA-300M $20 \mathrm{~kW}$ Hall Effect Thruster", 47th AIAA/ASME/SAE/ASEE Joint Propulsion Conference \& Exhibit, AIAA-2011-5521, San Diego, CA, 31 Jul.- 3 Aug., 2011.

${ }^{8}$ Soulas, G. C., et al., "Performance Test Results of the NASA-457M v2 Hall Thruster", 48th AIAA/ASME/SAE/ASEE Joint Propulsion Conference \& Exhibit, Atlanta, GA, 29 Jul.- 1 Aug., 2012.

${ }^{9}$ Mikellides, I. G., et al., "Magnetic shielding of the channel walls in a Hall plasma accelerator", Physics of Plasmas, Vol. 18, No. 3, doi:10.1063/1.3551583, Mar. 8, 2011, pp. 033501.

${ }^{10}$ Hofer, R. R. and Gallimore, A. D., "Recent Results from Internal and Very-Near-Field Plasma Diagnostics of a High Specific Impulse Hall Thruster", 28th International Electric Propulsion Conference, IEPC-2003-037, Toulouse, France, Mar., 2003.

${ }^{11}$ Jameson, K. K., "Investigation of Hollow Cathode Effects on Total Thruster Efficiency in a 6 kW Hall Thruster", Ph.D. Dissertation, Aerospace Engineering, University of California, Los Angeles, Los Angeles, CA, 2008.

${ }^{12}$ Reid, B. M., "The Influence of Neutral Flow Rate in the Operation of Hall Thrusters", Ph.D. Dissertation, Aerospace Engineering, University of Michigan, Ann Arbor, MI, 2008.

${ }^{13}$ Shastry, R., "Experimental Characterization of the Near-Wall Region in Hall Thrusters and its Implications on Performance and Lifetime", Ph.D. Dissertation, Aerospace Engineering, University of Michigan, Ann Arbor, MI, 2011.

${ }^{14}$ Manzella, D. M., "Scaling Hall Thrusters to High Power", Ph.D. Dissertation, Mechanical Engineering, Stanford University, Stanford, CA, 2005.

${ }^{15}$ Hofer, R. R., Peterson, P. Y., Gallimore, A. D., and Jankovsky, R. S., "A High Specific Impulse Two-Stage Hall Thruster with Plasma Lens Focusing", 27th International Electric Propulsion Conference, IEPC-2001-036, Pasadena, CA, 15-19 Oct., 2001.

${ }^{16}$ Hofer, R. R. and Gallimore, A. D., "The Role of Magnetic Field Topography in Improving the Performance of High-Voltage Hall Thrusters", 38th AIAA/ASME/SAE/ASEE Joint Propulsion Conference \& Exhibit, AIAA-2002-4111, Indianapolis, IN, 7-10 Jul., 2002.

${ }^{17}$ Mikellides, I. G., Katz, I., Kamhawi, H., and Vannoord, J. L., "Numerical Simulations of a 20-kW Class Hall Thruster Using the Magnetic-Field-Aligned-Mesh Code Hall2De", 32nd International Electric Propulsion Conference, 2011-244, Wiesbaden, Germany, 11-15 Sep., 2011.

${ }^{18}$ Herman, D. A., Shastry, R., Huang, W., Soulas, G. C., and Kamhawi, H., "Plasma Potential and Langmuir Probe Measurements in the Near-field Plume of the NASA 300M Hall Thruster", 48th AIAA/ASME/SAE/ASEE Joint Propulsion Conference \& Exhibit, Atlanta, GA, 29 Jul.- 1 Aug., 2012.

${ }^{19}$ Shastry, R., Huang, W., Herman, D. A., Soulas, G. C., and Kamhawi, H., "Plasma Potential and Langmuir Probe Measurements in the Near-field Plume of the NASA 457Mv2 Hall Thruster", 48th AIAA/ASME/SAE/ASEE Joint Propulsion Conference \& Exhibit, Atlanta, GA, 29 Jul.- 1 Aug., 2012.

${ }^{20}$ Brown, D. L., "Investigation of Flow Discharge Voltage Hall Thruster Characteristics and Evaluation of Loss Mechanisms", Ph.D. Dissertation, Aerospace Engineering, University of Michigan, Ann Arbor, MI, 2009.

${ }^{21}$ Huang, W., Kamhawi, H., and Shastry, R., "Farfield Ion Current Density Measurements before and after the NASA HiVHAc EDU2 Vibration Test", 48th AIAA/ASME/SAE/ASEE Joint Propulsion Conference \& Exhibit, AIAA-2012-4195, Atlanta, GA, 29 Jul.- 1 Aug., 2012.

${ }^{22}$ Reid, B. M. and Gallimore, A. D., "Near-field Ion Current Density Measurements of a 6-kW Hall Thruster", 31st International Electric Propulsion Conference, 2009-124, Ann Arbor, MI, 20-24 Sep., 2009. 
${ }^{23} \mathrm{Kim}, \mathrm{V}$., "Main physical features and processes determining the performance of stationary plasma thrusters", Journal of Propulsion and Power, Vol. 14, No. 5, 1998, pp. 736-743.

${ }^{24}$ Hofer, R. R., "Development and Characterization of High-Efficiency, High-Specific Impulse Xenon Hall Thrusters", Ph.D. Dissertation, Aerospace Engineering, University of Michigan, Ann Arbor, MI, 2004.

${ }^{25}$ Reid, B. M. and Gallimore, A. D., "Langmuir Probe Measurements in the Discharge Channel of a 6-kW Hall Thruster", 44th AIAA/ASME/SAE/ASEE Joint Propulsion Conference \& Exhibit, AIAA-2008-4920, Hartford, CT, 21-23 Jul., 2008. 